NBER WORKING PAPER SERIES

\title{
THE EFFECTS OF FISCAL CONSOLIDATIONS: THEORY AND EVIDENCE
}

\author{
Alberto Alesina \\ Omar Barbiero \\ Carlo Favero \\ Francesco Giavazzi \\ Matteo Paradisi \\ Working Paper 23385 \\ http://www.nber.org/papers/w23385 \\ NATIONAL BUREAU OF ECONOMIC RESEARCH \\ 1050 Massachusetts Avenue \\ Cambridge, MA 02138 \\ May 2017, Revised November 2017
}

For comments we thank Edoardo Acabbi, Daniel Cohen, Harald Hulig, and participants in the 2016 ASSA Meetings in San Francisco, at the 2015 ECFIN workshop "Expenditure-based consolidations: experiences and outcomes", at CEPR's 2015 ESSIM and at seminars at the NY Fed, the IMF, the University of Stockholm, the University of Chicago, Booth and the Paris School of Economics. We also thank Gualtiero Azzalini, Igor Cerasa, Giorgio Saponaro, Daniele Imperiale, Armando Miano and Lorenzo Rigon for outstanding research assistance. We gratefully acknowledge the support of IGIER at Bocconi University and of the Italian Ministry for Research and Universities through a 2015 PRIN grant prot. 2015FMRE5X. The views expressed herein are those of the authors and do not necessarily reflect the views of the National Bureau of Economic Research.

NBER working papers are circulated for discussion and comment purposes. They have not been peerreviewed or been subject to the review by the NBER Board of Directors that accompanies official NBER publications.

(0) 2017 by Alberto Alesina, Omar Barbiero, Carlo Favero, Francesco Giavazzi, and Matteo Paradisi. All rights reserved. Short sections of text, not to exceed two paragraphs, may be quoted without explicit permission provided that full credit, including $\odot$ notice, is given to the source. 
The Effects of Fiscal Consolidations: Theory and Evidence

Alberto Alesina, Omar Barbiero, Carlo Favero, Francesco Giavazzi, and Matteo Paradisi

NBER Working Paper No. 23385

May 2017, Revised November 2017

JEL No. E62,H60

\begin{abstract}
We investigate the macroeconomic effects of fiscal consolidations based upon government spending cuts, transfers cuts and tax hikes. We extend a narrative dataset of fiscal consolidations, with details on over 3500 measures for 16 OECD countries. We show that government spending cuts and cuts in transfers are much less harmful than tax hikes, despite the fact that nondistortionary transfers are not classified as spending. Standard New Keynesian models robustly match our results when fiscal shocks are persistent. Wealth effects on aggregate demand mitigate the impact of a persistent spending cut. Static distortions caused by persistent tax hikes cause larger shifts in aggregate supply under sticky prices.
\end{abstract}

\author{
Alberto Alesina \\ Francesco Giavazzi \\ Department of Economics \\ Universita' Bocconi and IGIER \\ Harvard University \\ Littauer Center 210 \\ Cambridge, MA 02138 \\ Via Guglielmo Röntgen, 1 \\ Milan 20136 \\ and IGIER \\ and also NBER \\ aalesina@harvard.edu \\ Omar Barbiero \\ Department of Economics \\ Harvard University \\ ITALY \\ and NBER \\ francesco.giavazzi@unibocconi.it \\ Matteo Paradisi \\ Department of Economics \\ Harvard University \\ Littauer 108 \\ Littauer Center \\ Cambridge, MA 02138 \\ 1805 Cambridge st \\ 02138, Cambridge \\ paradisi.matteo@gmail.com \\ obarbiero@g.harvard.edu \\ Carlo Favero \\ Department of Finance \\ Bocconi University and IGIER \\ Via Röntgen, 1 \\ 20136 Milano, ITALY \\ carlo.favero@unibocconi.it
}




\section{Introduction}

The literature on the macroeconomic effects of fiscal policies has found a wide range of estimates for fiscal multipliers and is far from having reached a consensus. A new result, however, is consistently confirmed by a number of recent papers (e.g. Alesina et al., 2015; Guajardo et al., 2014): fiscal consolidations implemented by raising taxes imply larger output losses compared to consolidations relying on reductions in government spending. The earlier literature had examined the effects of spending cuts adding up government consumption and transfers, and this is a serious limitation. In the present study, we disentangle transfers from tax and government spending measures and show that spending cuts are still much less recessionary than tax hikes. In fact the average cost of a spending based fiscal consolidation in terms of output losses is small. Instead, tax based adjustments cause deep and long lasting recession. ${ }^{1}$ Transfers, as predicted by theory, have small effects on GDP growth, but larger effects on private consumption. We verify that these results can be explained by a standard New-Keynesian model and we isolate the mechanism that could explain the observed heterogeneity.

This paper contributes to the literature on the effect of fiscal consolidations in three ways. First, by producing a new time-series with over 3500 exogenous shifts in fiscal variables categorized between direct and indirect taxes, transfers, and other government spending for 16 countries. Second, by simoultaneously estimating for the first time multipliers for three separate components of the budget: taxes, government transfer and public spending. This is crucial to understand whether previous results on government spending multipliers were driven by the counfunding effects of transfers and to draw a straightforward parallel with the theoretical literature. Third, we contribute by analytically studying the fiscal multipliers in a standard New-Keynsian model and by showing that, within this framework, the persistence of fiscal measures explains the heterogeneity in the output effect of different fiscal components.

We identify exogenous shifts in each fiscal variable building on, and further developing, the narrative approach pioneered by Romer and Romer (2010). ${ }^{2}$ Our database extends a set of narrative-identified "exogenous" fiscal stabilizations included in Devries et al. (2011) and considered "exogenous" because their adoption is not correlated with the economic

\footnotetext{
${ }^{1}$ This result is consistent with earlier evidence presented in Giavazzi and Pagano (1990), Alesina and Ardagna (2009) and Alesina and Ardagna (2012) obtained with inferior data and techniques.

${ }^{2}$ Other attempts at disaggregating fiscal adjustments can be found in Mertens and Ravn (2013), Romer and Romer (2016) and Perotti (2014). These papers, however, are limited to the U.S. and often only consider either the tax or the spending side of fiscal corrections.
} 
cycle. These consolidations are implemented either through tax increases or spending cuts in 17 OECD countries over the period 1978-2009. We extended their data by collecting additional information on every fiscal measure included in the consolidation plans, specifying details on its legislative source for a total of about 3500 different measures over the entire sample. We also extend the sample identifying the consolidation episodes occurred between 2009 and 2014, a particularly interesting period in light of the "austerity" plans adopted in many European countries. ${ }^{3}$ Our new database contains the magnitude and the details of each policy prescriptions, e.g. "rise in VAT rate by $2 \%$ ", "reduction in tax relief", "reduction of childbirth grant", "cut in public employees salaries". This approach allows us to assess with higher precision the magnitude and the exogeneity of every prescription. The former reduces the measurement error problem often associated with narrative measures. The latter allows us to flag those measures that are potentially "endogenous" and that may be overlooked if we were just recording their aggregate counterparts.

After having identified the fiscal measures, we organize the data into multi-year "plans", that is announcements of shifts in fiscal variables to be implemented over an horizon of several years, which is the way fiscal policy is implemented in the real world. To the extent that expectations matter, the multi-year nature of these announcements cannot be ignored without incurrring into omitted variable bias. After voting on the size of a multi-year plan, legislatures decide its composition. ${ }^{4}$ To account for this infratemporal coomposition, we split the sample into tax-based $(T B)$, consumption and investment-based $(C I B)$ and transfer-based $(T R B)$ fiscal plans depending on the largest among the three components over the horizon of the plan. Because these plans are, by assumption, mutually exclusive we can simulate each of them independently and evaluate the effect of counterfactual compositions of fiscal consolidations. ${ }^{5}$ In this way, all components are simoultaneously included in our model to avoid omitted variable bias. No previous study in the literature on narrative shocks has separately estimated multipliers of government consumption and investment, transfers, and taxes in such a way.

We find that plans based on reductions in spending (current and investment) or reduction in transfers have broadly the same effect on output. They both cause, on average, a mild recessionary effect after one year from the start of the consolidation, but this effect starts

\footnotetext{
${ }^{3}$ This new database, which is one of the contributions of the paper, is available for researchers who might wish to use it at the address www.igier.unibocconi.it/fiscalplans.

${ }^{4}$ In the case of euro area countries the size of the deficit reduction plan has to be agreed upon with the European institutions. The composition of the plan is left to local authorities.

${ }^{5}$ If we instead estimated the three components in isolation, we would only be able to simulate the "average" plan observed in the data, featuring the in-sample correlation among components.
} 
vanishing the following year. ${ }^{6}$ This is not an obvious result. It shows that the inclusion of transfers among other public spending measures is not the explanation for the effect of public spending found in previous studies. On the other hand, tax-based adjustments confirm to cause much larger output losses than expenditure-based fiscal consolidations. Tax-based plans also have long lasting recessionary effects: four years after the introduction of a taxbased plan worth one per cent of GDP, output is more than one percentage point lower than it would have been absent the consolidation. Consumption drops almost equally across components in the short-term, but recovers quickly for spending and transfer-based consolidations. Private investments strongly respond to taxes only, with a long term multiplier of -3 .

All results are robust to a battery of sensitivity checks. We perform our estimation on different samples by exluding one country at a time and one decade at a time. We also check that the estimates are unchanged when excluding the years of the last financial crisis and the post-Euro period. We repeat our estimation by excluding plans that do not have a clear-cut composition, i.e. the difference between the two largest components is smaller than $10 \%$ of the total. Heterogeneity in multipliers is also preserved when we separate indirect from direct taxes. Finally, we verify that the composition of fiscal plans is not correlated with past economic growth and contemporaneous structural reforms, which could drive the heterogeneity in the effects of different types of plans. Guajardo et al. (2014) argue that the difference in the effects of tax hikes and spending cuts is driven by different responses of monetary policy. We make two points. First, we estimate the response of short-tem interest rates to different compositions of fiscal plans and show that they are not significantly different from each other. Second, evidence on the aggregate version of our dataset in Alesina et al. (2015) shows that monetary policy does not drive the difference in the effect of tax-based and expenditure-based plans.

In the theoretical part of the paper, we ask which mechanisms could explain our estimates. We start from the standard New Keynesian model analyzed by Christiano et al. (2011) and we include four fiscal variables: labor taxes, consumption taxes, transfers and other government spending. Given our classification of spending and transfers in the empirical analysis, we can draw a parallel between government spending in the empirics and in the model. Because transfers are neutral, in the theoretical model we mostly focus on the heterogeneity between government spending and taxes. We compute analytically instantaneous multipliers in a linearized version of the model that excludes capital and assumes

\footnotetext{
${ }^{6}$ This result is in contrast with recent work by House et al. (2017) that estimate a multiplier of 2 for government spending cuts during the period 2010-2014 in Europe.
} 
that the government budget is always balanced (we relax these assumptions later). Running comparative statics on the persistence of fiscal variables, we show that the persistence can rationalize our empirical results. ${ }^{7}$ When fiscal policies are close to permanent, government spending cuts are less recessionary than tax hikes. The opposite is true if fiscal shocks are expected to quickly reverse. The behavior of the spending multiplier is consistent with Christiano et al. (2011), Woodford (2011) and Galì et al. (2007), but we also evaluate tax multipliers in relation to their persistence. In light of this, we establish that our empirical results are not consistent with the predictions of neoclassical models as discussed in Baxter and King (1993). In addition, the persistence of fiscal shifts could explain the difference between multipliers found in studies of fiscal stimuli, compared to studies of fiscal consolidations. Fiscal stimuli tend to be temporay and generate large spending multipliers. Fiscal consolidations are more permanent and generate very low spending multipliers. The opposite is true for taxes.

The fact that our theoretical results square with our empirical findings if the persistence of fiscal measures is high, should not come as a surprise. In our empirical analysis, fiscal consolidation shocks are once-and-for-all legislative fiscal changes. ${ }^{8}$ In the data collection we seldom encountered cases where previously implemented measures are reversed by the government. We also estimate a positive inter-temporal correlation of fiscal shocks in our data, indicating that rather than reversed, aggregate fiscal components typically accumulate over the course of fiscal plans.

The reason why the persistence of fiscal shocks is critical is the following. A cut in government spending has a negative demand effect, which causes a recession. But if the reduction in government spending is permanent, it will imply higher transfers forever, raising private consumption and partly compensating lower government spending. As a consequence, the drop in aggregate demand diminishes when the persistence of government cuts increases. Given price rigidities, firms must reduce their labor demand accordingly. For this reason, when the wealth effect on aggregate demand increases, output falls less. In the case of a wage tax increase, the output effect is purely explained by shifts in aggregate supply. Static labor distortions generate a decrease in labor supply which firms under sticky prices accommodate by cutting labor demand. A persistent increase in labor taxes makes the static effect on labor supply more permanent, increasing the wage tax multiplier.

\footnotetext{
${ }^{7}$ In principle, monetary policy also plays a small role because it is more accommodating in response to government spending cuts. However, when we introduce a monetary policy rule more sensitive to government spending cuts our results are unchanged.

${ }^{8}$ See also Coenen et al. (2012) for a discussion of the effectiveness of fiscal policies in relation to their persistence.
} 
We then extend the model to include capital and allow for fiscal policy to be carried out through multi-year plans. Adopting the calibration in Christiano et al. (2011) our simulations are consistent with our empirical results for the response of output, private consumption and private investment, both qualitatively and quantitatively. Announcements generate a curvature in the impulse response functions that matches the shape of our empirical estimates. The presence of capital amplifies the response of output to taxes: this is because the lower return on capital generated by the drop in labor supply tends to further reduce the capital stock. This effect is mitigated in the case of government spending-based and transfer-based consolidations as they cause smaller effects on labor supply.

We also verify the robustness of these results by studying scenarios of aggressive monetary policy, a small open economy with external government debt and a model with hand-to-mouth consumers that relaxes the Ricardian equivalence assumption of the classical New-Keynesian model. None of these features breaks the importance of persistence in explaining the heterogeneity in the effects of the different fiscal compoents.

Our paper relates to two branches of literature. On the empirical side, we contribute to the estimation of the macroeconomic effects of fiscal policies further developing the narrative approach by Romer and Romer (2010). The latter, together with Mertens and Ravn (2013), focus on the effect of different kinds of tax measures implemented in the US after World War II. On the spending side, the estimation of empirical multipliers either exploits increases in defense spending that are presumably exogenous to the business cycle, or the variation across states in government outlays. ${ }^{9}$ Romer and Romer (2016) are the first to study government transfers in isolation, with a narrative measure of Social Security benefit increases from 1952 to 1991 in the US and looking at the response of private consumption. Within the theoretical literature, we are not the first who identify the persistence of fiscal shocks to be a crucial element determining the size of fiscal multipliers. However, we show that it is the main variable robustly explaining the heterogeneous response of output to our three fiscal components and that it helps reconciling our results with what previous empirical studies have found. ${ }^{10}$.

\footnotetext{
${ }^{9}$ Work involving defense spending in the US includes: Barro and Redlick (2011); Ramey (2011b); Ramey and Zubairy (ming); Perotti (2014); Nakamura and Steinsson (2014). Chodorow-Reich et al. (2012); Clemens and Miran (2012); Serrato and Wingender (2011) exploits cross-state variation to estimate the effect of public spending on employment and output.

${ }^{10}$ Christiano and Eichenbaum (1992); Aiyagari et al. (1992), Baxter and King (1993), Burnside et al. (2004), Ramey and Shapiro (1998) and Ramey (2011a) compare temporary and permanent fiscal shocks in various versions of an $\mathrm{RBC}$ model. They demonstrate that persistent shocks to government spending generate higher multipliers than temporary changes. The result can be explained by wealth effects on labor supply. Christiano et al. (2011) derive analytical expressions for spending multipliers in a New-Keynesian model and
} 
The paper is organized as follows. In Section 2 we describe the data construction process and the classification of the various components of taxes and spending. Section 3 illustrates the concept of a "fiscal plan" and explains how the data are organized into plans. In Section 4 we present our empirical strategy and in Section 5 our results. Robustness is discussed in Section 6. Finally, Section 7 illustrates the theoretical model, its calibration, and uses it to investigate the channels underlying our results. The last Section concludes.

\section{Data Construction}

We identify "exogenous" shifts in fiscal variablesby using the narrative method. The latter attempts to solve the endogeneity problem by identifying, through direct consultation of the relevant budget documents, those innovations in fiscal policy that were not implemented with the objective of cyclical stabilization and can consequently be considered as exogenous for the estimation of the short-term output effects of fiscal consolidations. Devries et al. (2011) identified "exogenous" fiscal stabilizations implemented through tax increases and spending cuts in 17 OECD countries over the period 1978-2009. ${ }^{11}$ In their dataset, fiscal adjustments are classified as exogenous if $(i)$ they are geared towards reducing an inherited budget deficit or its long run trend, e.g. increase in pension outlays induced by population aging, or (ii) are motivated by reasons which are independent of the state of the business cycle, excluding adjustments motivated by short-run counter-cyclical concerns. We provide some examples of the motivations behind fiscal consolidations in Appendix A1.

\subsection{A new dataset of disaggregated fiscal shocks}

We reviewed and extended the fiscal measures identified by Devries et al. (2011) in two ways. First, we extended the sample to cover the years from 2009 to 2015 that were not

notice the opposite effect of the persistence of fiscal variables for the size of government spending multipliers, whose reason we discuss in Section 7.2. Galì et al. (2007) simulates a standard New-Keynesian model with and without rule-of-thumb consumers and non-competitive labor markets and numerically analyzes the multipliers on government spending, confirming that the multiplier decreases in the persistence of the fiscal shock. See also Denes et al. (2013) for multipliers on other fiscal components.

${ }^{11}$ The countries are: Australia, Austria, Belgium, Canada, Denmark, Finland, France, Germany, Holland, Ireland, Italy, Japan, Portugal, Spain, Sweden, United Kingdom, United States. In our emprical work we exclude Holland. The reason is that, checking the Dutch consolidations, we found a significant correlation with contemporaneous output growth. The reason likely lies in a particular feature of Dutch fiscal plans. In the Netherlands a law prescribes that the government sets fiscal targets at the beginning of its election term; in the following years deviations from these targets are only allowed for cyclical reasons. 
included in the original dataset, following previous work by Alesina et al. (2015). Second, we collected details on every fiscal measure included in the consolidation plans, specifying its legislative source for a total of about 3500 different measures over the entire sample. ${ }^{12}$ We gathered information on the content of each policy prescription e.g. "rise in VAT rate by $2 \%$ ", "reduction in tax relief", "reduction of childbirth grant", "cut in public employees salaries". We then classify each measure using the following categories: personal income direct taxes, corporate direct taxes, individual property taxes, corporate property taxes, taxes on goods and services, government consumption, public investments, public employees salaries, firm subsidies, $R \& D$ policies, corporate tax credits and deductions, individual tax credits and deductions, family and children policies, pension-related expenditure, unemployment benefits, health-related expenditures and other social security expenditures. In order to capture the inter-temporal dimension of fiscal policy - and thus to be able to reconstruct fiscal "plans" - we also distinguish measures that were unanticipated from announcements of future measures up to a five years horizon.

We have details to assess the magnitude and the exogeneity of every prescription. The former reduces the measurement error problem often associated with narrative measures. The latter allows us to flag those measures that are potentially "endogenous" and that may be overlooked if we were just recording their aggregate counterparts. We can then exclude such measures in our robustness tests. Our approach also provides more flexibility in the classification of every fiscal component: this is useful to check whether our results are sensible to classification assumptions. Finally, we provide higher flexibility that could be useful to other researchers who aim at using the data for different purposes. Data on single measures and their motivation, together with details on the procedure we followed to collect the data, are available online. ${ }^{13}$

Following a standard procedure, shifts in fiscal variables are measured relative to a baseline of no policy change. In order to measure the size of the fiscal shifts, we look exclusively at contemporaneous government documents - as both Devries et al. (2011) and Romer and Romer (2010) do - for two reasons. First, because retrospective figures reporting the realized change in fiscal variables are rarely available. Second, because realized changes in fiscal variables, unlike announcements, are likely to be affected by the economic consequences of a fiscal consolidation, for instance behavioral responses of labor supply

\footnotetext{
${ }^{12}$ We have also corrected a few inconsistencies in that dataset.

${ }^{13}$ Find all the information at www.igier.unibocconi.it/fiscalplans.
} 
which might affect tax revenues. All fiscal measures are scaled as percentage of GDP in the year before the change in policy is announced, according to the latest available information at the time Legislators vote on a budget. This avoids a simultanaeity issue that would arise if we used contemporaneous GDP. In any case, scaling all the measures using contemporaneous GDP makes virtually no difference. Data refer to the general government, except for the US, Canada and Australia, for which they only cover the federal government.

A requirement for the use of narrative fiscal shocks in studying the macroeconomic effect of fiscal policies is their unpredictability with respect to the economic cycle and past fiscal shocks. Our empirical methodology takes care of the inter-temporal correlation of fiscal shocks by analyzing "plans", rather than isolated measures (see Section 3). Moreover, we run several tests on our shocks and we do not find them to be predictable by GDP growth in previous years. Section 6.1 discusses our tests thoroughly. For illustrative purposes, Figure A.1 in appendix shows the aggregate time series of consolidations for the US and Europe with a discussion of their motivations.

\subsection{The classification of tax, spending and transfers}

We consider three broad categories: government consumption and investments, transfers and taxes. We have also experimented with a four-level disaggregation separating direct from indirect taxes: the result are reported in Section 6.3. The reason we do not separate direct and indirect taxes in the baseline specification is that there are only a few episodes of consolidations involving large changes in indirect taxes. We discuss this in further details in Section 3.

Government Spending and Investments Government consumption includes current expenditures for goods and services, public sector salaries and other employees compensation, the corresponding social insurance contributions, the managing cost of State-provided services such as education (public schools and universities, but also training for unemployed workers) and healthcare. Public investment includes all expenditures made by the government with the expectation of a positive return. The category includes government gross fixed capital formation expenditures (e.g. land improvement, plants, purchases of machinery and equipment, construction of roads and railways.) In other words, we classify as government consumption and investment everything that is not a direct resource transfer to citizens or corporations. Ideally, one would want to separate government consumption from government investment and check if the two multipliers differ. Their organization into 
plans prevents it since there are too few plans consisting mostly of shifts in government investment.

Transfers We define transfer every payment made by the government to private entities. The main economic feature of a transfers is that it does not affect the marginal rate of substitution between consumption and leisure. We include among transfers subsidies, grants, and other social benefits. For instance, transfers include all non-repayable payments on current account to private and public enterprises, social security, social assistance benefits, and social benefits distributed in cash and in kind.

Direct and Indirect Taxes We define direct every tax imposed on a person or a property that does not involve a transaction. We include in this component income, profits, capital gains and property taxes. We classify as direct all taxes levied on the actual or presumptive net income of individuals, on the profits of corporations and enterprises, on capital gains, whether realized or not, on land, securities, and other assets plus all taxes on individual and corporate properties. We also include in the category income tax credits and tax deductions.

Indirect taxes are those imposed on certain transactions involving the purchase of goods or services. Examples include VAT, sales tax, selective excise duties on goods, stamp duty, service tax, registration duty, transaction tax, turnover selective taxes on services, taxes on the use of goods or property, taxes on the extraction and production of minerals and profits of fiscal monopolies. This category also accounts for VAT exemptions.

\section{Fiscal Plans}

We study the effects of fiscal "plans", defined as announcements and implementation of shifts in fiscal variables over an horizon of several years.

A fiscal plan typically contains three components:

1. unexpected measures (announced upon implementation at time $t$ ), $e_{t}^{u}$;

2. measures implemented at time $t$, but which had been announced $j$ years before, $e_{t-j, t}^{a}$;

3. measures announced at time $t$, to be implemented in future years, where $j$ denotes the horizon of the announcement, $e_{t, t+j}^{a}$. 
As an illustrative example, Table 1 summarizes the fiscal consolidation measures introduced in Belgium in 1992-94. ${ }^{14}$ A first plan worth 2.3 of GDP was announced in 1992: it included both "unexpected" measures $\left(e_{t}^{u}\right)$ that went into effect immediately for a total of $1.85 \%$ of GDP and measures announced in $1992\left(e_{t, t+1}^{a}\right)$, but to be implemented the following year amounting to $0.47 \%$ of GDP. The plan was then revised in 1993, when the Belgian government adopted additional measures worth 0.52 percent of GDP for 1993, that we label as unexpected, and announced a 0.83 percent consolidation for the following year. In 1994, there were no additional announcements, the plan only consisted of previously approved measures and new measures worth $0.38 \%$ of GDP. ${ }^{15}$

\begin{tabular}{cccccc}
\hline Year & $e_{t}^{u}$ & $e_{t-1, t}^{a}$ & $e_{t, t+1}^{a}$ & $e_{t, t+2}^{a}$ & $e_{t, t+3}^{a}$ \\
\hline 1992 & 1.85 & 0 & 0.47 & 0 & 0 \\
1993 & 0.52 & 0.47 & 0.83 & 0 & 0 \\
1994 & 0.38 & 0.83 & 0 & 0 & 0 \\
\hline
\end{tabular}

Table 1: The multi-year plan introduced in Belgium (and then revised) in 1992 (\% of GDP)

Inter-temporal Dimension The inter-temporal feature of fiscal policy generates "fiscal foresight" because agents learn in advance future announced measures. As noted by Leeper et al. (2013), fiscal foresight prevents the identification of exogenous shifts in fiscal variables from VAR residuals. This is the reason for using a direct measurement of the shifts in fiscal variables, which is what the the narrative approach does. Equation (1) describes the correlation between the immediately implemented and the announced parts of a plan:

$$
e_{t, t+j}^{a}=\varphi_{j} e_{t}^{u}+v_{t}
$$

Overlooking announcements would mean assuming that they are uncorrelated with unanticipated policy shifts, incurring into the risk of omitted variable bias. As we shall see, this assumption of no correlation is violated in the data. The inter-temporal dimension

\footnotetext{
${ }^{14}$ See Appendix A1 for details on the motivation of this plan.

${ }^{15}$ Our maintained assumption is that plans are fully credible. The plans in our sample are in some cases amended on the fly: when this happens we treat the amendment as a surprise and we count it as a new plan. The assumption that plans are fully credible is strong and cannot be easily tested. Lack of credibility would arise if measures implemented differed from those that had been announced. This would require cleaning these measures, which are often reported as fractions of GDP, from the effects of unexpected shifts in output or inflation. Credibility is discussed in a theory context in Lemoine and Linde (2016). Our classification of plans could in some cases provide useful evidence on their credibility. For instance, we expect TRB plans, which, as reported in Table 4, often imply changes in social security legislation, to be less easily reversed, and thus more credible compared to $C I B$ plans.
} 
of the plan should also be preserved when simulating the impulse response functions that compute fiscal multipliers (see Section 4).

Infra-temporal Dimension A fiscal consolidation includes shifts in taxes $(T)$, in government consumption and investment $(C I)$ and in transfers $(T R)$. These measures are infratemporally correlated and their correlation poses a challenge to the simulation of the effects of a plan. Suppose we estimated a model projecting output growth on shifts in $T, C I$ and $T R$. The coefficients on the three fiscal variables would be determined by their in-sample correlation. As a consequence, we could only simulate the "average" fiscal plan preserving the correlations that we observe in the data. This, however, would not allow to pin down the effects of a counterfactual plan involving a different composition of fiscal shocks. The standard solution to this problem would be to decompose $T, C I$ and $T R$ into orthogonal shocks that can be simulated independently. This is a hard identification problem.

Alternatively, we could estimate a fully non-parametric model allowing for differential effects of all the potential compositions of fiscal plans. Because of limitations in sample size we reduce the dimensionality of the model by splitting the sample into tax-based $(T B)$, consumption-based $(C I B)$ and transfer-based $(T R B)$ plans depending on the largest among the three components (measured as a percent of GDP) over the horizon of the plan. Because these plans are, by assumption, mutually exclusive it is possible to simulate each of them independently. 
Table 2: Plans Classification, 1981-2014

\begin{tabular}{lcccc}
\hline Country & TB & CB & TRB & \\
\hline \hline AUS & 3 & 1 & 3 & \\
AUT & 2 & 0 & 6 & \\
BEL & 6 & 0 & 9 & \\
CAN & 8 & 7 & 4 & \\
DEU & 6 & 0 & 8 & \\
DNK & 3 & 1 & 4 & \\
ESP & 8 & 7 & 0 & \\
FIN & 2 & 1 & 6 & \\
FRA & 4 & 4 & 2 & \\
GBR & 5 & 2 & 4 & \\
IRL & 7 & 6 & 1 & \\
ITA & 5 & 6 & 7 & \\
JPN & 4 & 5 & 1 & \\
PRT & 6 & 5 & 0 & \\
SWE & 0 & 0 & 5 & \\
USA & 5 & 1 & 1 & \\
\hline \hline Tot. & 74 & 46 & 61 & $\mathbf{1 8 1}$ \\
\hline
\end{tabular}

Note. Plans are classified according to the category that is most affected. The Table reports new plans only, excluding years when no new measures where introduced.

Table 2 shows the number of plans in each category. There are 46 plans based on reductions in spending (current plus investment) and 61 on transfers. TB plans are more frequent and amount to 74 plans out of a total of $181 .{ }^{16}$ We do not distinguish direct and indirect tax-based plans in our baseline specification as we would only have 21 episodes of indirect tax-based consolidations. Nevertheless, we show the results of this alternative specification in Section 6.3. Table 3 documents the composition of the average plan in each category: for instance, the total size of the average $C I B$ plan amounts to 0.83 per cent of GDP, of which about $58 \%$ is associated with reductions in government consumption and investments. Table 3 shows that the main component of the plan accounts for a significantly larger share over the total plan than any other component. Moreover, comparing standard errors to averages, the main component always results as the one with the smaller relative standard error. This suggests that residual components tend to be more noisy as they are not the main focus of the plan. Shares do not sum to one because we cannot always classify

\footnotetext{
${ }^{16}$ Following our definition, we count as plan every year when a new measure is introduced. Not every year in which a fiscal shock occurs is labeled as a plan: this is the case in all years when no new measures are announced and the government implements measures voted upon in previously years.
} 
a minor share of fiscal measures under the three categories.

Table 3: Average composition of plans (1981-2014)

\begin{tabular}{|c|c|c|c|c|c|c|c|c|}
\hline \multirow{3}{*}{ Type of plan } & \multirow{3}{*}{$\mathrm{N}$} & \multicolumn{7}{|c|}{ Average composition ( $\%$ of GDP) } \\
\hline & & \multirow{2}{*}{$\frac{\text { Total Plan }}{\% \text { GDP }}$} & \multicolumn{2}{|c|}{$\operatorname{Tax}$} & \multicolumn{2}{|c|}{ Consumption } & \multicolumn{2}{|c|}{ Transfer } \\
\hline & & & $\%$ GDP & $\%$ Plan & $\%$ GDP & $\%$ Plan & $\%$ GDP & $\%$ Plan \\
\hline Tax Based & 74 & $\begin{array}{c}1.56 \\
(1.52)\end{array}$ & $\begin{array}{c}\mathbf{1 . 0 1} \\
(0.81)\end{array}$ & 0.65 & $\begin{array}{c}0.25 \\
(0.45)\end{array}$ & 0.16 & $\begin{array}{c}0.17 \\
(0.36)\end{array}$ & 0.11 \\
\hline Consumption Based & 46 & $\begin{array}{c}1.45 \\
(1.62)\end{array}$ & $\begin{array}{c}0.23 \\
(0.66)\end{array}$ & 0.16 & $\begin{array}{c}\mathbf{0 . 8 3} \\
(0.72)\end{array}$ & 0.58 & $\begin{array}{c}0.22 \\
(0.33)\end{array}$ & 0.15 \\
\hline Transfer Based & 61 & $\begin{array}{c}1.69 \\
(1.41)\end{array}$ & $\begin{array}{c}0.41 \\
(0.64)\end{array}$ & 0.24 & $\begin{array}{c}0.33 \\
(0.35)\end{array}$ & 0.20 & $\begin{array}{c}\mathbf{0 . 7 1} \\
(0.63)\end{array}$ & 0.42 \\
\hline
\end{tabular}

Note. Mean values computed in each category. Columns denoted by GDP report the measure as a ratio with respect to the GDP in the previous year. Column denoted by Plan show the average with respect to the total plan size. Average shocks of fiscal components do not sum to the total plan because of residual measures not classified under any of the three categories.

Standard Deviation in parenthesis.

Our strategy for classifying multi-year fiscal plans does not lead to marginal cases in which a label is attributed on the basis of a negligible difference between the two largest components. It appears from the data that in most cases a political decision was made first as to the nature of the fiscal consolidation. In only 30 out of 181 new plans the difference in share between the two biggest components is lower than 10 percent of the total fiscal correction. In only 16 cases the main component is less than 5 percent bigger than the second largest component. Our results are robust when we exclude plans where these differences are small and our results are virtually unchanged. Our results are also robust to dropping all plans in which the share of the dominant component is less than 50 per cent of the total adjustment. As discussed in the robustness section using this criterion lead us do drop 22 tax-based plans, 14 consumption-based plans, and 23 transfer-based plans. 
Table 4: Average composition of plans by category of spending and taxes (1981-2014)

\begin{tabular}{lcccc}
\hline & \multicolumn{4}{c}{ Average Size (\% of GDP) } \\
& \multicolumn{1}{c}{ Size, unanticipated measures } & Size, announced measures \\
\cline { 2 - 5 } & Mean & Sd & Mean & Sd \\
\hline & & & & \\
Consumption & & & & \\
Government Consumption & 0.132 & $(0.231)$ & 0.058 & $(0.173)$ \\
Salaries & 0.064 & $(0.177)$ & 0.020 & $(0.090)$ \\
Public investment & 0.06 & $(0.178)$ & 0.006 & $(0.035)$ \\
& & & & \\
Taxes & & & & \\
$\quad$ Total Direct & 0.379 & $(0.753)$ & 0.077 & $(0.548)$ \\
Income & 0.185 & $(0.365)$ & 0.048 & $(0.273)$ \\
Personal & 0.08 & $(0.266)$ & 0.032 & $(0.211)$ \\
Corporate & 0.064 & $(0.147)$ & -0.004 & $(0.115)$ \\
Property taxes & 0.03 & $(0.139)$ & -0.007 & $(0.106)$ \\
Other Direct & 0.019 & $(0.096)$ & 0.008 & $(0.072)$ \\
$\quad$ Total Indirect & 0.229 & $(0.380)$ & 0.084 & $(0.187)$ \\
& & & & \\
Transfers & & & & \\
Pensions & 0.135 & $(0.261)$ & 0.046 & $(0.090)$ \\
Firm Subsidies & 0.064 & $(0.119)$ & 0.015 & $(0.046)$ \\
Tax Credits and Deductions & 0.008 & $(0.067)$ & 0.021 & $(0.083)$ \\
Unemployment benefits & 0.05 & $(0.129)$ & 0.039 & $(0.078)$ \\
Other Subsidies & 0.161 & $(0.324)$ & 0.102 & $(0.281)$ \\
\hline \hline
\end{tabular}

Note. Mean values computed for each category for the period 1981-2014. Data on Germany restricted to the period 1992-2014.

Table 4 shows a detailed breakdown of the three main components across all type of plans. For each component we document the fraction of the adjustment that was unexpected and the fraction that was announced for future implementation. Governments seem to implement consistent policies over time since the relative ranking of the magnitudes for every sub-component is unchanged when comparing unexpected to announced measures. Government consumption is the largest sub-component in CIB plans. Salaries and investment are equally employed as unexpected measures, but cuts in salaries come with higher future announcements. Pensions are the largest component to be cut among government transfers averaging $0.135 \%$ of GDP among unexpected measures. Firm subsidies are the second largest sub-component with about half the impact on average. Indirect taxes are the largest in magnitude among all fiscal measures with an average of $0.23 \%$ of GDP in 
unexpected measures per year. Corporate taxes are the largest sub-component of income taxes, although we could not precisely measure the breakdown between corporate and personal taxes. Property taxes seem to be the only component that on average is reversed over time. ${ }^{17}$

Finally, Table 5 shows the length of the three types of plans. The $75 \%$ of plans have more than a one-year horizon, implying that the vast majority of fiscal consolidations include announcements of future measures. TRB plans, on average, last longer, probably reflecting the time it takes to change social security rules. The three types of plans seem to be fairly similar across all the other dimensions. Note that when a plan is changed while being implemented we call it a new plan.

Table 5: Time Horizon of Fiscal Plans

\begin{tabular}{lccccccc}
\hline & \multicolumn{6}{c}{ Horizon of Plans in Years } \\
\cline { 2 - 8 } Type of Plan & $\mathbf{1}$ & $\mathbf{2}$ & $\mathbf{3}$ & $\mathbf{4}$ & $\mathbf{5}$ & $\mathbf{6}$ & Average \\
\hline CIB & 16 & 17 & 3 & 4 & 1 & 5 & 2.39 \\
TB & 19 & 25 & 9 & 12 & 5 & 4 & 2.61 \\
TRB & 12 & 23 & 4 & 6 & 9 & 7 & 2.97 \\
All Plans & 47 & 65 & 16 & 22 & 15 & 16 & \\
\hline \hline
\end{tabular}

\section{Estimation}

We study the effects of three types of plans (CIB, TB and TRB) estimating a panel with country and time fixed effects for 16 OECD countries over the sample of annual data 19782014. Plans are heterogeneous both in their effects on per capita output growth and in their inter-temporal correlation structure i.e. the $\varphi^{\prime} s$ in (1). We estimate the following system

$$
\Delta y_{i, t}=\alpha+\left[\sum_{j=0}^{2}(\overbrace{\beta_{\mathbf{j}} e_{i, t-j}^{u}}^{\text {Unexpected }}+\overbrace{\gamma_{\mathbf{j}} \underbrace{e_{i, t-j, t}^{a}}_{\text {Past }}+\delta \underbrace{e_{i, t, t+j+1}^{a}}_{\text {Future }}}^{\text {Announced }})\right]\left[\begin{array}{c}
C B_{i, t} \\
T R B_{i, t} \\
T B_{i, t}
\end{array}\right]+\lambda_{i}+\chi_{t}+u_{i, t}
$$

\footnotetext{
${ }^{17}$ Only a few countries in our sample use property taxes as part of a fiscal consolidation. Italy is the country, in our sample, that used property taxes more intensively. It is also the country responsible for the negative average effect of announcements: this is explained by the fact that in more than one occasion Italy announced that newly introduced property taxes would be reversed in subsequent years. We return to this point below.
} 
where the index $i$ refers to the countries in the panel and the index $t$ refers to the year a plan is first introduced. $e_{i, t-j}^{u}, e_{i, t-j, t}^{a}$ and $e_{i, t, t+j}^{a}$ are, respectively, the unexpected, past and future components of the total magnitude of the plan. $\beta_{\mathbf{j}}=\left[\begin{array}{lll}\beta_{j}^{C B} & \beta_{j}^{T R B} & \beta_{j}^{T B}\end{array}\right]$ is a 3element coefficient vector corresponding to the unanticipated component of the three plans. Likewise, $\gamma_{\mathbf{j}}$ corresponds to the measures implemented in period $t$ that had been previously announced (allowing for lagged effects) and $\delta$ to the announced measures $e_{i, t, t+j}^{a}$ for the future period $t+j$. Each of the three elements of $\beta_{\mathbf{j}}, \gamma_{\mathbf{j}}$ and $\delta$ corresponds to one of the three types of plans studied. $C B_{i, t}, T R B_{i, t}$ and $T B_{i, t}$ are dummies that take the value 1 depending on the component with largest size over the total plan (see section 3 for details). $\lambda_{i}$ and $\chi_{t}$ are country and time fixed effects.

The estimation of (2) and (1) allows for the two sources of heterogeneity investigated in this paper: the intra-temporal and the inter-temporal dimension. The inter-temporal dimension is key to understanding one of the main innovation of this paper. Early narrative studies collapse unanticipated and announced measures using $\left(e_{i, t}^{u}+e_{i, t, t+j}^{a}\right)$ and neglect $e_{i, t-j, t^{*}}^{a}{ }^{18}$ Equation (2) allows instead for unanticipated measures, announcements and implementation of previously announced measures to have different multipliers.

We estimate the inter-temporal correlation between the unexpected and the announced part of a plan by using the auxiliary regression in (1) for each plan-specific correlation. We limit the horizon to two-year-ahead announcements as this is the plan horizon used in estimation. The model in (2) is then estimated by Seemingly Unrelated Regressions (SUR) to take into account the simultaneous cross-country correlations of residuals.

There are two aspects to note in (2). First, we have restricted the coefficients $\delta$ to be equal for all announced measures $e_{i, t, t+k}^{a}(k=1,2)$. We have done so to increase power and because the dynamic effect is already captured by the coefficients on $e_{i, t-1, t}^{a}$. Second, (2) is a truncated moving average. Thus, the efficient estimation of the relevant parameters requires that the left-hand side variables are time-series with a low degree of persistence, as it is the case for output growth. ${ }^{19}$

\footnotetext{
${ }^{18}$ Ramey (2011b) also recognizes the importance of anticipated future shocks by including in the empirical specification professional forecasts based on the Survey of Professional Forecasters.

${ }^{19}$ This specification is, in our view, the appropriate way to estimate the parameters of an impulse response function when the aim is to capture the average effect of a fiscal plan. In this context the Linear Projection method proposed by Jordà (2005) and extensively used in the literature to analyze the effects of isolated fiscal shocks would not allow to properly track the effects of plans, as discussed in Alesina et al. (2016).
} 


\section{Results}

We use estimates of (2) to simulate the effects of fiscal adjustment plans with different composition on various macroeconomic variables: output growth, consumption growth, the growth of fixed capital formation, indices of consumers and business confidence and the short-term interest rate. ${ }^{20}$ The panel includes the 16 OECD countries listed above. The data are at a yearly frequency and the sample extends from 1978 to 2014.

Figure 1 reports estimates of $\varphi_{1}$ and $\varphi_{2}$ from (1) for the three type of plans we analyze. Consolidations plans based on increases in taxes feature the highest inter-temporal correlation, indicating that $T B$ plans typically take the form of sequences of tax changes distributed over time. In other words, they are not front-loaded. $C I B$ plans, instead, have the smallest (but statistically significant) inter-temporal correlation, indicating that governments tend to front-load cuts in current spending and investments.

Figure 1: Inter-temporal Persistence by Type of Plan

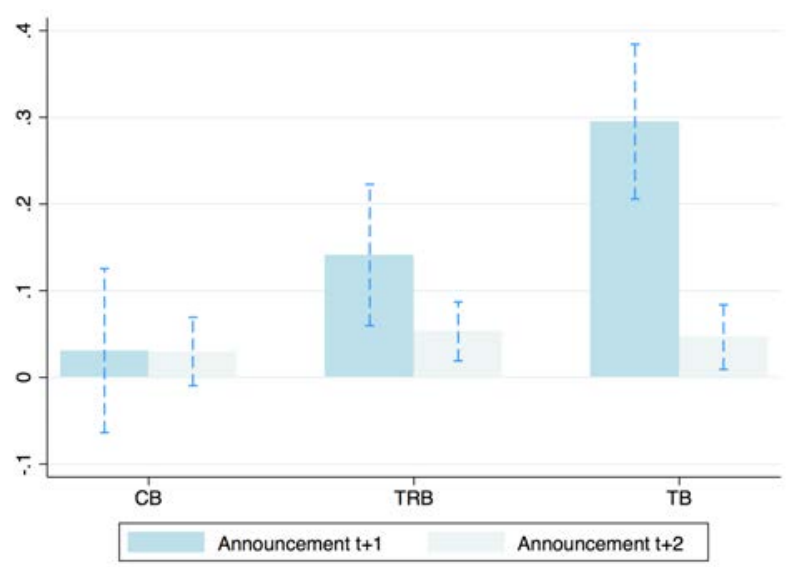

Table 6 reports the estimated coefficients $\beta_{0}, \gamma_{0}$, and $\delta$ on the three components of each type of plan at time $t$ in model (2). Note that most coefficients are significant. However, to properly evaluate the average effects of the three fiscal plans we must combine the coefficients in Table 6 with the inter-temporal coefficients in Figure 1, in impulse response form.

\footnotetext{
${ }^{20}$ Our non-fiscal macro data come from: Thomson Reuters, Datastream and the OECD Economic Outlook database. Datastream was used to download time series for the Economic Sentiment Indicators originally produced by the European Commission. The series for private final consumption expenditures and gross fixed capital formation along with the other macroeconomic variables are from the OECD Economic Outlook database.
} 
Table 6: Summary of estimated coefficients of regression (2)

\begin{tabular}{lccc}
\hline Type of plan & $\beta_{0}$ & $\gamma_{0}$ & $\delta$ \\
\cline { 2 - 4 } Tax-based & -0.54 & -0.66 & -0.15 \\
& $(0.10)$ & $(-0.16)$ & $(0.11)$ \\
Consumption-based & -0.21 & -0.16 & -0.36 \\
& $(0.13)$ & $(0.31)$ & $(0.17)$ \\
Transfer-based & & & \\
& -0.08 & -0.28 & -0.30 \\
\hline \hline
\end{tabular}

Figure 2 reports the impulse responses of output growth, consumption and investment to the introduction of multi-year plans whose total size is normalized to be one percent of GDP. Note that the heterogeneity in the $\varphi^{\prime} s$ implies that an initial unanticipated correction of one per cent of GDP will generate plans of different size depending on the inter-temporal structure of the plan. To make our results comparable across plans, we normalize the sum of current and future shifts in fiscal variables to be one percent of GDP. We report two standard errors bands. $T R B$ plans are marked in green; plans based on reductions in current and investment spending in blue; plans based on tax hikes in red. Responses are cumulated over time, so that the points along the impulse response functions measure the deviation of an outcome from its level absent the change in fiscal policy. 
Figure 2: Impulse Response Functions

\section{GDP}

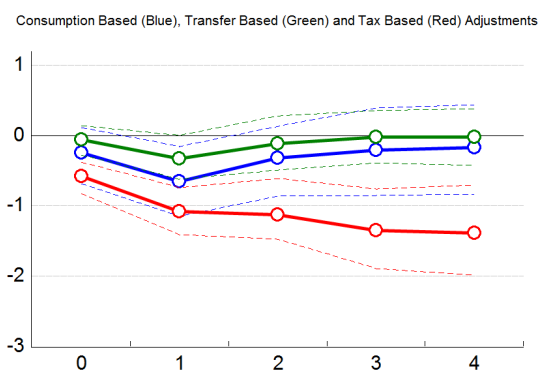

Consumption

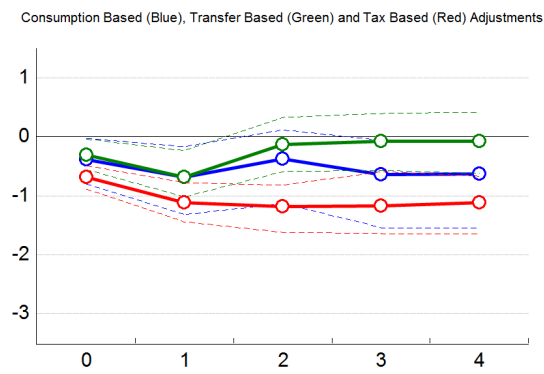

Investment

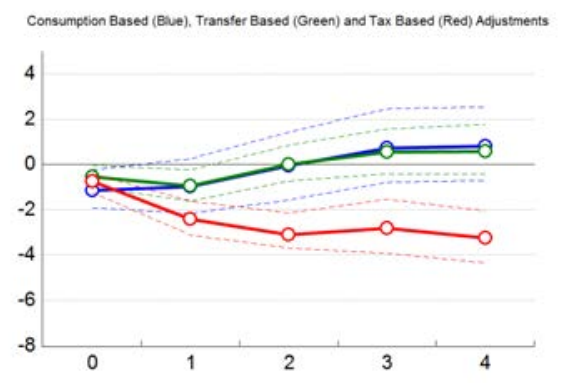

Note. Impulse response functions computed on the sample 1979-2014.

Starting from the effects on output growth, $T B$ plans are significantly more recessionary than $C I B$ and $T R B$ plans throughout, particularly since two years after the policy shift. This shows that the inclusion of transfers among other public spending measures is not the cause of the mild effect of expenditure cuts found in previous studies. CIB and TRB plans exhaust their mild and non-statistically significant recessionary effect two years after a plan is introduced. $C I B$ plans are significantly recessionary after one year before converging to a zero impact. $T B$ plans, on the contrary, have a long lasting effect on output growth, estimated to be around 1.3 percentage points. This multiplier is smaller than the value reported in Romer and Romer (2010) for a response to a tax shock, but close to that reported in Blanchard and Perotti (2002), although the type of policy shift that we analyze is different

Studying the effects on the disaggregated components of output, we find that most of the difference in medium-term output growth between $T B$ and the other two types of plans is accounted for by investment. ${ }^{21}$ After the introduction of a $T B$ plan, investment falls up

\footnotetext{
${ }^{21}$ This is consistent with results in Alesina et al. (2015) and Alesina et al. (2002).
} 
to 2 percentage points compared to a 1 percentage point in the case of $C I B$ and $T R B$, where the drop recovers in two years. Private consumption falls by one percent following the introduction of a $T B$ plan and by less than one percent in the case of $C I B$ and $T R$ plans. Consistently with Romer and Romer (2016), consumption responds in the short-term to changes in transfers and recovers in two years, while it remains slightly negative in the case of $C I B$ plans.

Figure 3: Impulse Response Functions for Additional Outcomes

ESI Consumer Confidence

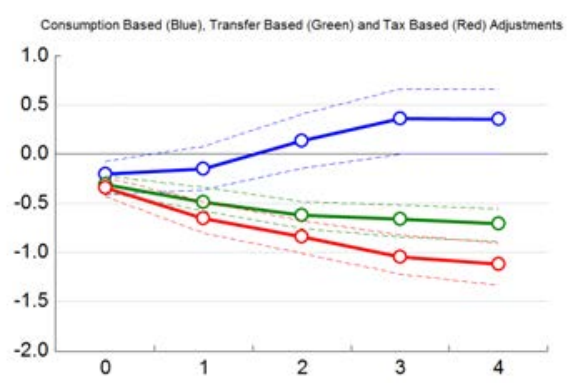

ESI Investment Confidence

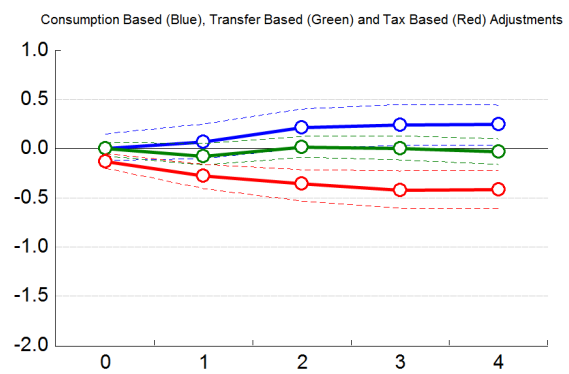

Note. Impulse response functions computed on the sample 1979-2014.

Figure 3 shows the response of consumer confidence and business confidence. The latter is consistent with results on investment for all three plans. Consumers confidence - unlike consumption growth - responds positively to a cut in government spending and negatively to a cut in transfers. Several reasons could explain why consumer confidence does not reflect changes in actual consumption expenditure. Although a cut in government consumption may boost confidence on the overall stability of the economy, this may trigger an incentive to save if the inter-temporal elasticity of substitution is low. Alternatively, if government consumption is complementary to private consumption, consumers may feel more confident but still decide to cut purchases. Cuts in transfers may motivate consumers to work more in response to a wealth-effect on labor supply and sustain consumption. More simply, consumers could be liquidity constrained and thus unable to translate improved confidence into higher consumption. 


\section{Discussion and Robustness}

\subsection{Exogeneity of plans}

Hernandez de Cos and Moral-Benito (2013) and Jordà and Taylor (2016) point out that fiscal adjustments constructed with the narrative approach are predictable, either by their own past or by past economic variables. The solution for predictability by shifts in past fiscal variables is to consider plans rather than collapsing them into shocks. Predictability from past economic variables, and in particular from output growth, deserves more attention. Hernandez de Cos and Moral-Benito (2013) describe fiscal adjustments through a dummy variable that takes the value of one when an adjustment is implemented and zero otherwise, and find that such a dummy is predictable based on information available at time $t-1$. This procedure overlooks the fact that there are two sources of identification of narrative adjustments: the timing of a fiscal correction and its size. Transforming fiscal adjustments into a dummy completely neglects size. ${ }^{22}$ These concerns regarding predictability can be addressed studying the effects of the introduction of a fiscal plan within a panel VAR that controls for the cycle and for lagged government revenues and expenditures, as done in Alesina et al. (2016). ${ }^{23}$ In this case the impulse responses do not significantly differ from those obtained implementing a limited information approach, that is a truncated MA regression such as the one in (2).

\subsection{Country Styles}

In our baseline results we have assumed that the inter-temporal style of a fiscal plan (the estimated $\varphi$ 's) varies depending on its composition. Here we allow it to vary across countries. The assumption is that each country has its own style in the design of fiscal plans, which is the same for all three types of plans: $T B, T R B$ and $C I B$. Table A.1 in appendix reports the estimated country-specific $\varphi$ 's.

When we simulate the impact on output growth of a fiscal consolidation worth one percent of GDP, using country-specific $\varphi^{\prime} s$ the results are very similar to those obtained

\footnotetext{
${ }^{22}$ This result is reiterated by the fact that we have verified that GDP does not Granger-cause the narrative fiscal consolidations shocks, according to the procedure by Toda and Taku (1995) which shows no Granger causality on a panel VAR with one lag, and $10 \%$ Granger causality on a panel with two lags. When the procedure is repeated country-by-country, only Italy's GDP is found to Granger cause fiscal consolidations. When we exclude Italy from the sample, all results are virtually unchanged.

${ }^{23}$ Predictability of fiscal shocks does not invalidate the consistency of the estimates (as it does not rule out weak exogeneity), though it could be a problem when models are simulated to retrieve impulse responses.
} 
using plan-specific $\varphi$ 's.

\subsection{Four-level disaggregation: separating direct from indirect taxes}

There are only 21 episodes whose dominant component is an increase in consumption taxes, and most of these episodes are concentrated in a few countries. ${ }^{24}$ Although the observations are too few to produce reliable results, we introduce indirect-tax based consolidations in Figure 4 to illustrate the robustness of our baseline results.

The multipliers associated with plans mostly based on increases in indirect taxes vary depending on the country considered. Figure 4 shows the results for two of the countries in our sample that did engage in some indirect-based consolidations: France and Germany. ${ }^{25}$ $C I B$ and $T R B$ plans have almost exactly the same effect as in the case with three components. The effect of consolidations plans mostly based on direct taxes have the same effect as those found aggregating the two types of taxes. The effects of plans mostly based on increases in indirect taxes, instead, appear to depend on the country-specific inter-temporal style of the plan: they are more or less recessionary according to how far in advance fiscal measures are announced.

Figure 4: Country-specific impulse response for the four-component version of the model

FRA

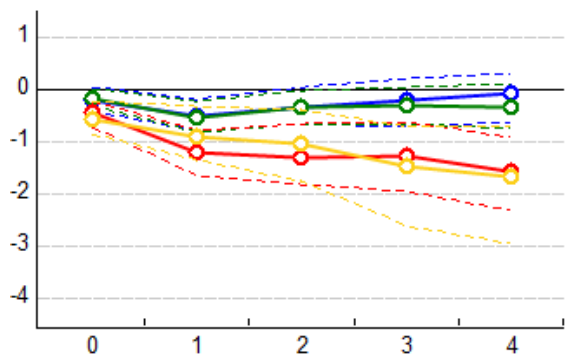

DEU

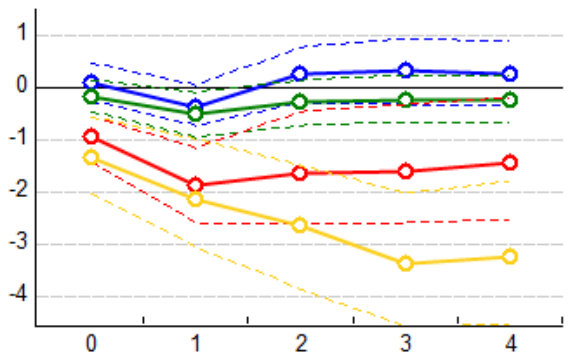

Note. Impulse response functions computed on the sample 1979-2014. Direct Tax-Based plan in red, Indirect Tax-Based plan in yellow, Transfer-Based plan in green, Public Consumption-Based plan in blue.

\footnotetext{
${ }^{24}$ Austria, Spain, France, the United Kingdom, Japan, Germany and Ireland.

${ }^{25}$ Note that the two panels in Figure 4 rely exactly on the same estimates in (2) and are different only because the $\varphi$ 's are different in the two countries.
} 


\subsection{Different Samples and Alternative Criteria for Selection of Plans}

As a second robustness exercise we have repeated the estimation using the sample 19811997 (pre-Euro sample), and the sample 1981-2007 (pre-financial crisis). ${ }^{26}$ We have also repeated the estimation excluding one country at a time. We have done so because fiscal consolidations were concentrated in specific historical periods (see Figure A.1 in appendix) and because consolidations differed in the extent and way they were implemented in different periods. None of the above replications generated results that were significantly different from the baseline. ${ }^{27}$ We have also repeated the estimation excluding all plans in which the difference in share between the two largest components of the fiscal adjustment was lower than 10 percent of the total consolidation. This eliminates plans for which a classification is borderline. Results are virtually unchanged as showed in Figure A.4 in Appendix C. Finally, we concentrated only on plans whose dominant componet was at least 50 per cent of the total adjustment (this criterion led us to drop 22 tax-based plans, 14 consumption-based plans and 23 transfer-based plans). The results, shown in Figure A.5 in Appendix C, support the evidence of the baseline model that tax-based adjustments are significantly more costly in terms of growth while the effect of consumption-based adjustments and transfer based adjustments is much less recessionary and not significantly different from each other.

\subsection{Contemporaneous economic reforms}

Economic reforms implemented along with a fiscal correction could affect the size of fiscal multipliers. ${ }^{28}$ For instance, it may be the case that $C I B$ plans are usually introduced along with product or labor market liberalizations that have a positive effect on output growth, partially compensating the negative impact of the consolidation. Using as a proxy the change in the OECD indexes of product and labor market reforms, we run a probit specification to check whether contemporaneous reforms affect: $i$ ) the probability of introducing a fiscal consolidation plan, and $i$ ) the type of plan, given that a new plan is introduced. The results of this exercise are reported in Table A.2, in Appendix C. There is no correlation between the timing or the composition of fiscal consolidations and the implementation of structural reforms. This does not exclude that reforms might interact with a fiscal plan and that accompanying policies might dampen the effect of a fiscal correction. But the finding

\footnotetext{
${ }^{26}$ See Figure A.3 in Appendix C.

${ }^{27}$ Results are available upon request.

${ }^{28}$ See also Alesina et al. (2017) for a discussion of contemporaneous economic reforms.
} 
is reassuring on the possibility that the heterogeneity of different types of plans might be the product of systematic differences in contemporaneous reforms.

\subsection{Monetary Policy}

Different responses of monetary policy to consolidation plans with alternative compositions could confound our results. For instance, our heteregeneity could be driven by the central bank cutting interest rates more in response to a $C I B$ or $T R B$ plan, compared to a $T B$ plan. To address this, we first evaluate the response of short term interest rates to the various types of plans and we report it in Appendix C. The response to $C I B$ and $T B$ plans is positive and the two are overlapping and not statistically different from each other. $T R B$ plans generate a non-significant 20 basis points drop in the short-term interest rate and we cannot reject that the response is significantly different from $C I B$ and $T B$ plans. This implies that monetary policy does not explain - at least not entirely - the observed heterogeneity in output effect, contrary to what argued by Guajardo et al. (2014). Further evidence on the aggregate version of this dataset in Alesina et al. (2015) shows that monetary policy does not drive the difference in the effect of tax-based and expenditure-based plans by estimating a VAR model including interest rate shocks.

\section{Model}

Which theoretical channels could be responsible for the observed heterogeneity between alternative fiscal stabilization designs? We address this question using a New Keynesian closed-economy DSGE model extended to incorporate the fiscal variables we have analyzed in Section 5. ${ }^{29}$ Except for tax distortions and for the presence of four fiscal instruments, the model is identical to Christiano et al. (2011), CER in what follows. Because of our classification of spending and transfers in the empirical analysis, we can draw a parallel between government spending in the empirics and in the model. This would not be possible if transfers were part of government spending in the data. For these reasons, and because transfers are neutral, in what follows we mostly focus on the heterogeneity between government spending and taxes. At the end of this Section we extend our framework to include external debt in an open economy. Finally, in Section 7.3, in order to

\footnotetext{
${ }^{29}$ This is not the only model that can yield heterogeneous responses to alternative fiscal plans. Another example would be a two-sectors model with different production technologies in the private and public sector, as studied, for instance, in Pappa et al. (2015).
} 
match the assumptions underlying our empirical evidence, we extend the model to allow for fiscal policy to be carried out through multi-year plans, for capital accumulation, and for non-Ricardian agents.

\subsection{Model Setup}

The representative agent maximizes her lifetime time-separable utility

$$
\max _{C_{t}, N_{t}, G_{t}} E_{0} \sum_{t=0}^{\infty} \beta^{t} U\left(C_{t}, N_{t}, G_{t}\right)
$$

subject to the budget constraint $\left(1+\tau_{t}^{c}\right) P_{t} C_{t}+B_{t+1}=\left(1-\tau_{t}^{d}\right) W_{t} N_{t}+T R_{t}+\left(1+i_{t}\right) B_{t}$. $C_{t}$ denotes time $t$ consumption, $N_{t}$ the amount of hours worked, $P_{t}$ is the price level, $W_{t}$ the nominal wage rate, $B_{t}$ is a one-period nominal risk-free bond, and $\beta$ is the discount factor. The government can use four fiscal instruments: $\tau_{t}^{d}$, a direct tax rate on wages, $\tau_{t}^{c}$, a sales tax, $G_{t}$, nominal government consumption and $T R_{t}$, government transfers. As in CER, the budget is balanced period-by-period through endogenous changes in non-distortionary transfers.

The production side of the economy is standard. The final good is produced by competitive firms using a constant elasticity of substitution aggregator of intermediate goods $Y_{t}=\left[\int_{0}^{1} Y_{t}(i)^{\frac{\varepsilon-1}{\varepsilon}} d i\right]^{\frac{\varepsilon}{\varepsilon-1}}$. Intermediate goods $Y_{t}(i)$ are produced by monopolists - employing labor and no capital - according to $Y_{t}(i)=N_{t}(i)$. We introduce capital later. The monopolist sets prices as in Calvo (1983): the probability that in period $t$ she can reset her price $P_{t}(i)$ is $(1-\theta)$.

We assume that fiscal variables follow exogenous processes:

$$
\begin{aligned}
G_{t+1} & =G_{t}^{\rho} \exp \left(\varepsilon_{t+1}^{g}\right) \\
1+\tau_{t+1}^{d} & =\left(1+\tau_{t}^{d}\right)^{\rho} \exp \left(\varepsilon_{t+1}^{d}\right) \\
1+\tau_{t+1}^{c} & =\left(1+\tau_{t}^{c}\right)^{\rho} \exp \left(\varepsilon_{t+1}^{c}\right)
\end{aligned}
$$

where the $\varepsilon^{\prime} s$ are iid shocks and $\rho$ denotes their persistence, assumed to be the same for all three fiscal shocks. The resource constraint of the economy is

$$
Y_{t}=C_{t}+G_{t}
$$

Monetary policy is determined by a standard Taylor rule, where $\phi_{\pi}$ measures how ag- 
gressively the nominal interest rate responds to inflation:

$$
i_{t}=\beta^{-1}\left(1+\pi_{t}\right)^{\phi_{\pi}}-1
$$

\subsection{Instantaneous Multipliers}

Consider, as in CER, the case of non separability between consumption and leisure and separability with respect to government spending:

$$
u\left(C_{t}, N_{t}, G_{t}\right)=\frac{\left[C_{t}^{\gamma}\left(1-N_{t}\right)^{1-\gamma}\right]^{1-\sigma}}{1-\sigma}+v\left(G_{t}\right)
$$

We computed analytically the instantaneous multipliers of the three fiscal components for a first order approximation of the model. Analytical expressions are shown in Appendix B1. Since our data mostly refers to permanent policy changes we are interested in how multipliers are affected by the persistence parameter $\rho$. Figure 5 shows the magnitude of the instantaneous multipliers as a function of $\rho$ when we adopt the same calibration as in CER. In order to make the multipliers comparable across components, we compute the responses of output to a shift of each fiscal component equivalent to 1\% of GDP. Therefore, in the case of taxes we plot the multiplier corresponding to a $1 \%$ increase in revenues over GDP, assuming the tax base is at the steady-state level.

Figure 5: Instantaneous Multiplier as a Function of Fiscal Shock Persistence

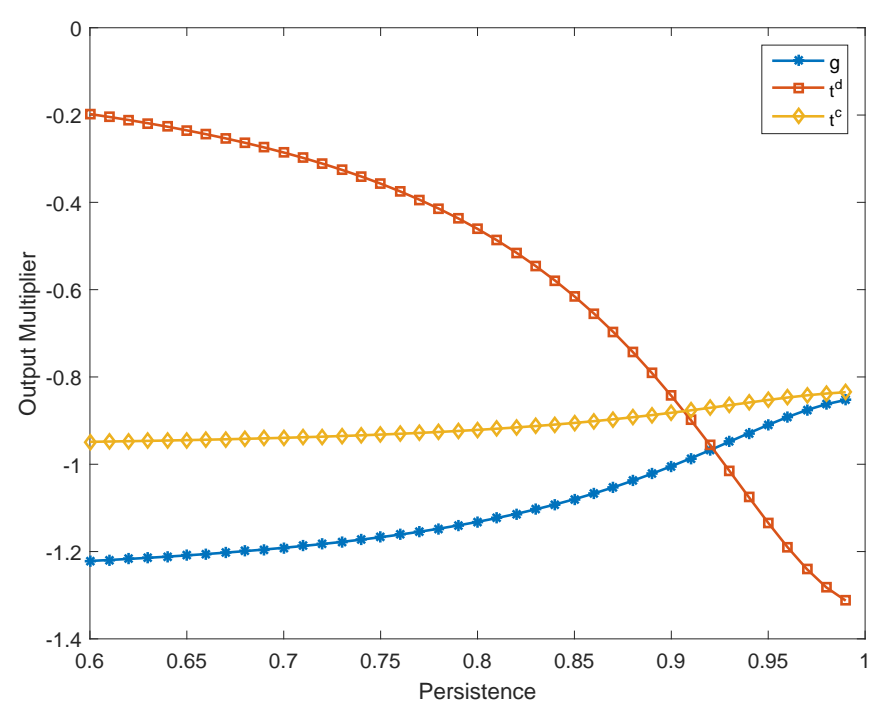


Size of multipliers and persistence The instantaneous multiplier of wage taxes - measured in output deviation from the steady state - is smaller (in absolute value) compared to that associated with consumption taxes or government spending when persistence is low. The lines cross and direct taxes display larger negative effects on output when the fiscal shifts are persistent. This is because the multipliers for spending and consumption taxes are slightly decreasing (in absolute value) in persistence, while the multiplier for direct taxes rapidly increases (in absolute value) with persistence, going from around 0.2 for $\rho=0.7$ to 1.3 when $\rho=0.99$. This result is consistent with our empirical findings, because all fiscal plans estimated in Section 5 are permanent (i.e. with a high $\rho$ ) shifts in fiscal policy.

Figure 5 also helps reconciling our model with previous theoretical results which found a tax multiplier smaller than the spending multiplier in models where fiscal components have low persistence e.g. Denes et al. (2013). In general, the persistence of fiscal shifts is a crucial aspect to explain the difference between the multipliers of each fiscal component in a fiscal stimulus, compared to a fiscal consolidation. Fiscal shocks tend to be temporay and generate large spending multipliers. Fiscal consolidations are more permanent and generate low spending multipliers. The opposite is true for taxes. The behavior of the spending multiplier in Figure 5 is consistent with the one discussed in Christiano et al. (2011), Woodford (2011) and Galì et al. (2007) in different versions of the New Keynesian model. ${ }^{30}$

Aggregate demand and supply To better grasp the intuition on the main channels responsible for the result in Figure 5 consider, following Denes et al. (2013), the aggregate demand (AD) and aggregate supply (AS) curves derived from a log-linearized version of

\footnotetext{
${ }^{30} \mathrm{We}$ also show that the multipliers of government spending and wage taxes can be higher than 1 (in absolute value), when we assume that government spending shocks have low persistence and monetary policy does not respond to the output gap. If we introduced a trade-off between output and inflation in the Taylor rule, we would obtain a spending multiplier below 1 , but the relative magnitude of the three multipliers would remain the same. We report in Appendix C Figure A.6 how the multipliers would change under an alternative Taylor rule that responds to output with $\phi_{y}=0.125$ as in Smets and Wouters (2007). New Keynesian models typically deliver low spending multipliers (see Smets and Wouters, 2007) unless additional frictions such as rule-of-thumb consumers, demand-determined employment or zero lower-bound are added. For instance, Woodford (2011) studies a zero-lower bound economy, Galì et al. (2007) have a positive share of rule-of-thumb consumers together with a non-competitive labor market and Nakamura and Steinsson (2014) introduce fixed nominal interest rates. See Ramey (2011a) for a general discussion about the size of spending multipliers in New-Keynesian models.
} 
the model:

$$
\begin{aligned}
A D: & \hat{\pi}_{t}=-\frac{1-\rho}{\phi_{\pi}-\rho}\left[D_{y} \hat{y}_{t}+D_{g} \hat{g}_{t}+D_{\tau^{s}} \hat{\tau}_{t}^{c}\right] \\
A S: & \hat{\pi}_{t}=\frac{\kappa}{1-\beta \rho}\left[S_{y} \hat{y}_{t}-S_{g} \hat{g}_{t}+S_{\tau^{s}} \hat{\tau}_{t}^{c}+S_{\tau^{w}} \hat{\tau}_{t}^{d}\right]
\end{aligned}
$$

Where $\hat{y}_{t}=\log \left(Y_{t} / Y^{s s}\right), \hat{g}_{t}=\left(G_{t} / Y_{t}-G^{s s} / Y^{s s}\right), \hat{\tau}_{t}^{d}=\left(\tau_{t}^{d}-\tau^{d, S S}\right)$ and $\hat{\tau}_{t}^{c}=\left(\tau_{t}^{c}-\tau^{c, S S}\right)$. The AD and AS curves describe how output and inflation respond to changes in the economic environment, including fiscal shocks. The coefficients $D_{y}, D_{g}, D_{\tau^{s}}, S_{y}, S_{g}, S_{\tau^{s}}, S_{\tau^{w}}$ are functions of the parameters of the model and their analytical expressions are reported in Appendix B2. Under the model's calibration these coefficients are all positive and do not depend on the persistence parameter $\rho$. This parameter amplifies the output elasticities $D_{y}$ and $S_{y}$ and the intercepts corresponding to the shifts in fiscal variables.

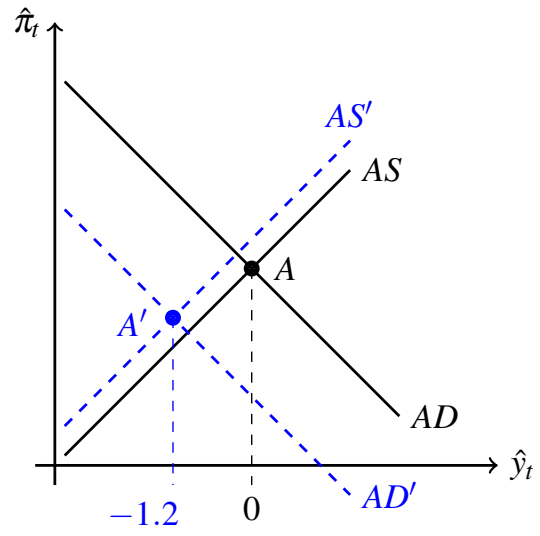

(a) Low persistence

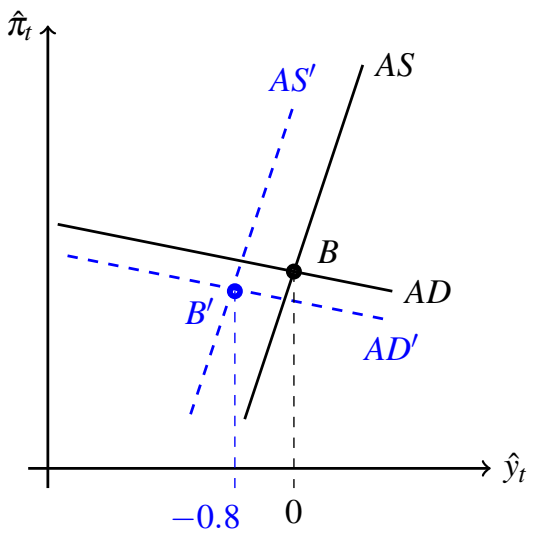

(b) High persistence

Figure 6: The output effect of a cut in government spending

Figure 6 compares the same cut in $\hat{g}_{t}$ in an economy with low shock persistence (panel a) and in one where persistence is higher (panel b). In both cases output and prices decrease, but the effects are smaller when the shock is more persistent. A cut in $\hat{g}_{t}$ has two effects on aggregate demand and supply. First, the demand curve shifts inward, due to the direct effect of lower demand from the government. Second, the supply curve also shifts inward. Workers lower their labor supply as they expect higher transfers in the future, this leads to an increase of firms marginal costs. With a persistence of $\rho=0.6$, the new equilibrium implies a shift from point $A$ to point $A^{\prime}$, with a multiplier of 1.2. When persistence is higher $(\rho=0.98)$ the shifts in the demand and supply curves change. On the one hand, 
the demand and supply elasticities are higher because the persistent nature of fiscal shocks makes consumers more sensitive to change in prices and firms more aggressive in their price settings. On the other hand, the present value of transfers increases with the persistence of the spending cuts. The result is that aggregate demand reacts less after accounting for the direct reduction in public spending and the response of private consumption, but labor supply falls more because of the wealth effect.

When facing lower aggregate demand, firms constrained by price rigidities must adjust their labor demand downwards. The latter effect is stronger when persistence is low and dominates over labor supply forces. In a Neoclassical economy, prices would instantly adjust under the two alternative values of $\rho$ and the wealth effect on labor supply would dominate. This is why RBC models deliver an opposite prediction for the relation between the spending multiplier and $\rho$ (see Aiyagari et al., 1992; Baxter and King, 1993). The result presented above is independent of the specification of preferences: it holds under preferences in (3) and under separability between consumption and leisure.



(a) Low persistence

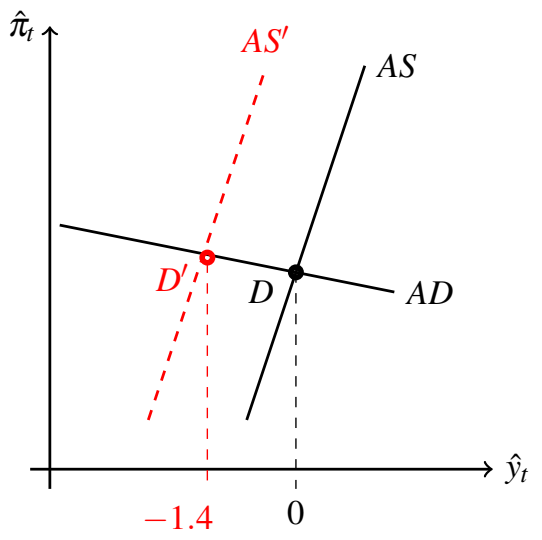

(b) High persistence

Figure 7: The output effect of a wage tax increase

Figure 7 shows the effect of an increase in $\hat{\tau}_{t}^{d}$ under low (panel a) and high (panel b) persistence. In both cases output decreases and prices increase. Contrary to what happened in the case of a reduction in government consumption, the multiplier increases with persistence. An increase in $\hat{\tau}_{t}^{d}$ only has a direct effect on aggregate supply, as can be seen in (4) and (5). This happens because $\hat{\tau}_{t}^{d}$ creates a wedge in the labor market but does not distort demand directly. As in the case of reductions in government consumption, higher persistence makes the elasticities of supply and demand higher. Static labor distortions generate a decrease in labor supply which firms under sticky prices accommodate by cutting labor 
demand. A persistent increase in labor taxes makes the static effect on labor supply more permanent, increasing the wage tax multiplier.

For consumption taxes the intuition is straightforward. Such taxes distort the Euler equation. An increase in $\tau^{c}$ that only lasts for a short period induces agents to postpone consumption. As a consequence, output decreases the lower is $\rho$. On the contrary, in the case of high persistence, when $\tau^{c}$ is expected to remain high for a long time the consumption path is flatter and the impact on output smaller.

Persistence of fiscal variables in our data The results presented in this paragraph square with our empirical findings if the persistence of fiscal measures is high. In our data collection we recorded as negative anticipated or unanticipated shocks every case in which fiscal consolidation measures are reversed by the government in the years following the beginning of the plan, and we found very few cases of this type. We also estimated the inter-temporal correlation of fiscal shocks over a two-year horizon (see Figure 1) and we found only positive or zero coefficients, indicating that rather than reversed, aggregate fiscal components typically accumulate over the course of the plan. ${ }^{31}$

Monetary policy Following a cut in government expenditures, inflation is expected to fall since firms' marginal costs are lower, while following an increase in the wage tax, it is expected to increase. This implies that the central bank will respond less aggressively to a decrease in spending. We have tested the sensitivity of our results to monetary policy by computing the instantaneous multipliers under a Taylor rule targeting both output gap and inflation. In this case, the central bank should react less aggressively to a tax cut, given the higher recessionary effects of taxes. We verified that the relative effects of the three fiscal components remains the same, even assuming that the central banker equally responds to inflation and output. The results for a standard calibration of the Taylor rule are presented in Figure A.6 in Appendix C. Our result would only break down at the zero lower-bound. ${ }^{32}$ In this case, a distortionary labor tax turns expansionary, given that higher taxes boost inflation, implying lower real interest rates and thus higher demand (Christiano et al., 2011; Denes et al., 2013). The level of persistence of our data makes this case not suitable for theoretical study, given that a sufficiently high persistence of fiscal variables

\footnotetext{
${ }^{31}$ Additional evidence on the high persistence of fiscal variables comes from previous works by Nakamura and Steinsson (2014) and Smets and Wouters (2007) that estimate persistence $A R(1)$ coefficients on government spending of 0.93 and 0.97 , respectively.

${ }^{32}$ See Farhi and Werning (2016) for a detailed discussion of fiscal multipliers at the zero-lower bound.
} 
boosts expected inflation so much that the economy would exit the zero lower-bound right away. ${ }^{33}$ Moreover, we do not wish to focus on the zero-lower-bound case because most of our empirical sample refers to years where the nominal interest rate was positive. Previous work by Alesina et al. (2015) and Alesina et al. (2016) on consolidation measures in 2009-2013 also did not find different effects on the economy compared to earlier fiscal consolidations carried out in "normal" times.

Open Economy Opening up the economy to trade in goods and financial assets does not change our results on fiscal policy. Our numerical simulations show that, if anything, opening up to trade produces even more heterogeneity between the effects of public spending cuts and tax hikes. We have verified this result with both floating and pegged exchange rates and with incomplete asset markets. ${ }^{34}$ We provide the details of the model and some intuition behind these results for the case of a government spending cut and a wage tax increase in Appendix B3. For a more detailed analysis of different tax mechanisms in an open economy we refer to Galì and Monacelli (2005) and Farhi et al. (2014).

\subsection{Extensions}

We extend the model in three directions. First, we introduce capital to evaluate the response of investment to fiscal adjustments. This is important since our empirical results suggest that the response of investment is critical in determining the observed difference between various plans. Second, we introduce fiscal plans in the form discussed in section 5. This will allow us to simulate the effect of a fiscal consolidation within a framework that matches the one used to obtain our empirical results. Third, we add sticky wages to match with the standard assumptions of the New Keynesian literature. ${ }^{35}$

Household Capital accumulates according to the following rule

$$
K_{t+1}=I_{t}+(1-\delta) K_{t}-\phi\left(\frac{I_{t}}{K_{t}}\right) K_{t}
$$

where $\phi(\cdot)$ is a standard convex adjustment cost function. ${ }^{36}$ Debt is in the form of

\footnotetext{
${ }^{33}$ See Christiano et al. (2011) and Nakamura and Steinsson (2014).

${ }^{34}$ Results are available upon request.

${ }^{35}$ In order to model sticky wages, we assume that firms set wages as in Calvo (1983), with probability of being able to revise the wage $1-\theta_{w}$. Results are virtually unchanged in a model with flexible wages.

${ }^{36}$ We use the following expression: $\phi\left(\frac{I_{t}}{K_{t}}\right)=\frac{\sigma_{I}}{2}\left(\frac{I_{t}}{K_{t}}-\delta\right)^{2}$.
} 
one-period bonds. $B_{t}$ are the units of the numeraire good that are paid by bonds carried from period $t-1$ into period $t$. In each period the household chooses consumption, capital and bond investment solving the following problem

$$
\max _{C_{t}, N_{t}, B_{t}, K_{t+1}, I_{t}} E_{0} \sum_{t=0}^{+\infty} \beta^{t} U\left(C_{t}, N_{t}, G_{t}\right)
$$

subject to the sequence of budget constraints

$$
\left(1+\tau_{t}^{c}\right) C_{t}+I_{t}+\frac{B_{t+1}}{P_{t}}=\left(1-\tau_{t}^{d}\right) w_{t} N_{t}+r_{t} K_{t}+\left(1+i_{t}\right) \frac{B_{t}}{P_{t}}+\frac{\Pi_{t}}{P_{t}}+T R_{t}+\tilde{T}_{t}
$$

Government The government budget constraint is

$$
G_{t}+T R_{t}+\tilde{T}_{t}=\tau_{t}^{d} w_{t} N_{t}+\tau_{t}^{c} C_{t}
$$

$G_{t}+T R_{t}$ are total outlays (government consumption plus transfers) while revenues are $\tau_{t}^{d} w_{t} N_{t}+\tau_{t}^{c} C_{t} . \tilde{T}_{t}$ is an additional transfer that balances the budget period-by-period. ${ }^{37}$ To describe the structure of fiscal plans we assume that taxes and spending components evolve as follows ${ }^{38}$

$$
\begin{aligned}
G_{t} & =(1-\rho) G_{s s}+\rho G_{t-1}+e_{t}^{G}+\sum_{s=1}^{3} e_{t, t-s}^{a, G} \\
T R_{t} & =(1-\rho) T R_{s s}+\rho T R_{t-1}+e_{t}^{T R}+\sum_{s=1}^{3} e_{t, t-s}^{a, T R} \\
\tau_{t}^{d} & =(1-\rho) \tau_{s s}^{d}+\rho \tau_{t-1}^{d}+e_{t}^{\tau^{d}}+\sum_{s=1}^{3} e_{t, t-s}^{a, \tau^{d}} \\
\tau_{t}^{c} & =(1-\rho) \tau_{s s}^{c}+\rho \tau_{t-1}^{c}+e_{t}^{\tau^{c}}+\sum_{s=1}^{3} e_{t, t-s}^{a, \tau^{c}}
\end{aligned}
$$

For each of the four rules we can distinguish two different parts. The first two terms represent a standard $A R(1)$ process with persistence determined by $\rho$, which we assume to be the same for all fours fiscal variables. Steady state values calibrate the average taxation

\footnotetext{
${ }^{37}$ Under Ricardian equivalence the effect of transfers is neutral on consumption and output. We therefore use this variable in order to ensure a balanced budget and avoid explosive paths of debt without introducing distortions that would not allow to isolate the effect of other fiscal variables.

${ }^{38} \mathrm{We}$ introduce $T R_{t}$ for the sake of exposition. However, this is the same type of transfers as $\tilde{T}_{t}$ used to balance government budget and hence have a neutral economic effect.
} 
and spending in the sample. The second part also contains two terms: the first refers to unanticipated fiscal measures, the second to the implementation of measures announced in the past. We assign a value of $\rho=0.99$ to simulate a highly persistent plan. Results do not change qualitatively as long as $\rho$ is sufficiently high. $e_{t}^{G}, e_{t}^{T R}, e_{t}^{\tau^{d}}, e_{t}^{\tau^{c}}$ denote the unanticipated component of each fiscal variable. They are defined as follows

$$
\begin{aligned}
e_{t}^{G} & =-\varepsilon_{t} Y_{s s}\left(C I B_{t} \phi^{G, C B}+T R B_{t} \phi^{G, T R B}+T B_{t} \phi^{G, T B}\right) \\
e_{t}^{T R} & =-\varepsilon_{t} Y_{s s}\left(C I B_{t} \phi^{T R, C B}+T R B_{t} \phi^{T R, T R B}+T B_{t} \phi^{T R, T B}\right) \\
e_{t}^{\tau^{d}} & =\varepsilon_{t} \frac{Y_{s s}}{w_{s s} N_{s s}}\left(C I B_{t} \phi^{\tau^{d}, C B}+T R B_{t} \phi^{\tau^{d}, T R B}+T B_{t} \phi^{\tau^{d}, T B}\right) \\
e_{t}^{\tau^{c}} & =\varepsilon_{t} \frac{Y_{s s}}{C_{s s}}\left(C I B_{t} \phi^{\tau^{c}, C B}+T R B_{t} \phi^{\tau^{c}, T R B}+T B_{t} \phi^{\tau^{c}, T B}\right)
\end{aligned}
$$

where $\varepsilon_{t}$ is a stochastic shock whose size depend on the magnitude of the unexpected component of the fiscal plan. To make impulse responses comparable to their empirical counterparts, each plan activates all four fiscal components according to the $\phi$ coefficients. The $\phi^{\prime} s$ are such that $\phi^{Z, J B}$ is the share of fiscal component $Z$ in a $J$-based adjustment, calibrated to be consistent with the actual composition of fiscal plans in our historical sample, as reported in Table A.4 in Appendix C.

The terms $e_{t, t-s}^{a, Z}$ in (9)-(12) represent - for each fiscal component $Z$ - the implementation in period $t$ of measures announced in periods $t-s, s=1,2,3 .{ }^{39}$ The anticipated part of the fiscal plan (announced at time $t-s$ for implementation in $t$ ) has the following structure for a generic component $Z$

$$
e_{t, t-s}^{a, Z}=\varphi_{s, Z} e_{t-s}^{Z}
$$

where the $\varphi^{\prime} s$ are those presented in Figure 1. These estimates, which add up to a positve number smaller than one, imply high persistency of the corrections in our simulated plans. In fact, when $\rho$ is close to one, corrections are permanent unless the annnounced part of the plan exactly compensates the unexpected corrections (i.e. su sum of the $\varphi^{\prime} s$ is -1). Figure 8 shows the simulated shifts in spending and revenues as percentage of steadystate output. ${ }^{40}$ The first period shock is unexpected, while additional expected shocks are

\footnotetext{
${ }^{39}$ Announcement of future measures do not appear in these four equations directly, but show up in their reduced forms. These equation thus correspond to those we estimated empirically.

${ }^{40}$ Revenues are computed using the steady state values of the different tax bases and assuming no behavi-
} 
announced for period two and three at time 1 and their magnitude is defined by the planspecific $\varphi$ 's. In every period past shocks carry over depending on the persistence parameter $\rho$. Note that each plan activates all four components, albeit in different percentages. This generates the average correlation between fiscal components that we see in the data.

Figure 8: Fiscal Plans
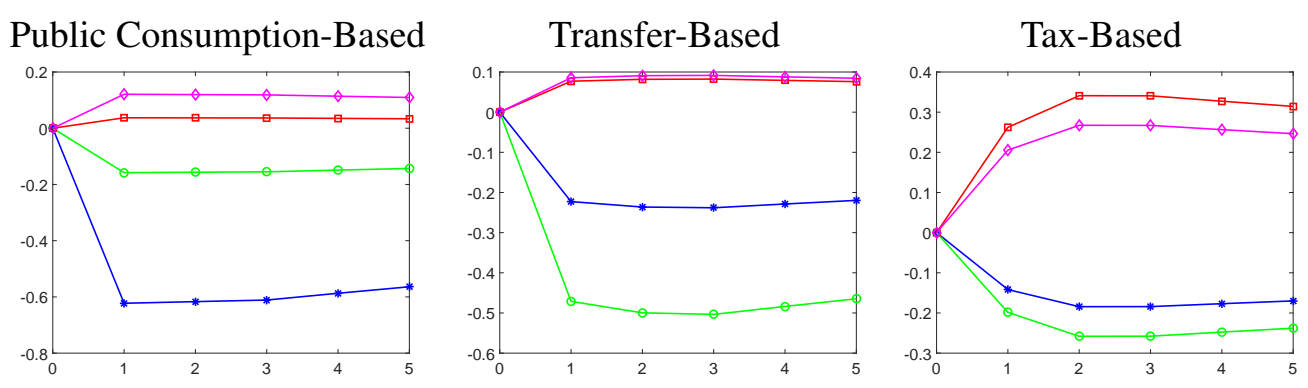

Government Consumption $\bullet-$ Government Transfers $\rightarrow$-Direct Taxes $\triangleleft$-Indirect Taxes

\subsection{Simulation Results}

We follow CER and Galì et al. (2007) for calibration of most parameters. We chose a discount factor $\beta=0.99$, risk aversion $\sigma=2, \gamma=0.29$, investment adjustment cost $\sigma_{I}=17$, capital share $\alpha=0.3$ and price and wage stickiness $\theta_{p}=\theta_{w}=0.85$. The share of transfer and public consumption spending in steady state are $G_{s s} / Y_{s s}=T R_{s s} / Y_{s s}=0.2$, while the wage tax rate and the indirect tax rate under steady state are 0.36 and 0.2 respectively, calibrated from sample averages in OECD and European Commission data. See Table A.3 in Appendix $\mathrm{C}$ for more details. ${ }^{41}$

We plot impulse responses for the first four years after the initial shock. Unexpected and announced shifts in fiscal variables occur during the first quarter of each year. The shock occurring in year 1 is unexpected, while the second and third year shocks are announced at time $t=1$ according to the plan-specific $\varphi^{\prime} s$ estimated in our sample. The overall size of the fiscal consolidation is set to be one percent of steady state output.

Figure 9 presents the impulse response functions of output, consumption and investment for each of the three types of fiscal consolidation plans. Every variable is expressed in deviation from steady state, exactly as in our empirical results.

oral response.

${ }^{41}$ The parameters are calibrated on quarterly data. To match our empirical results, which are based on annual data, we aggregate ex-post our simulations transforming them at yearly frequency using the average deviation from the steady state in the year. 
Figure 9: Model Simulations
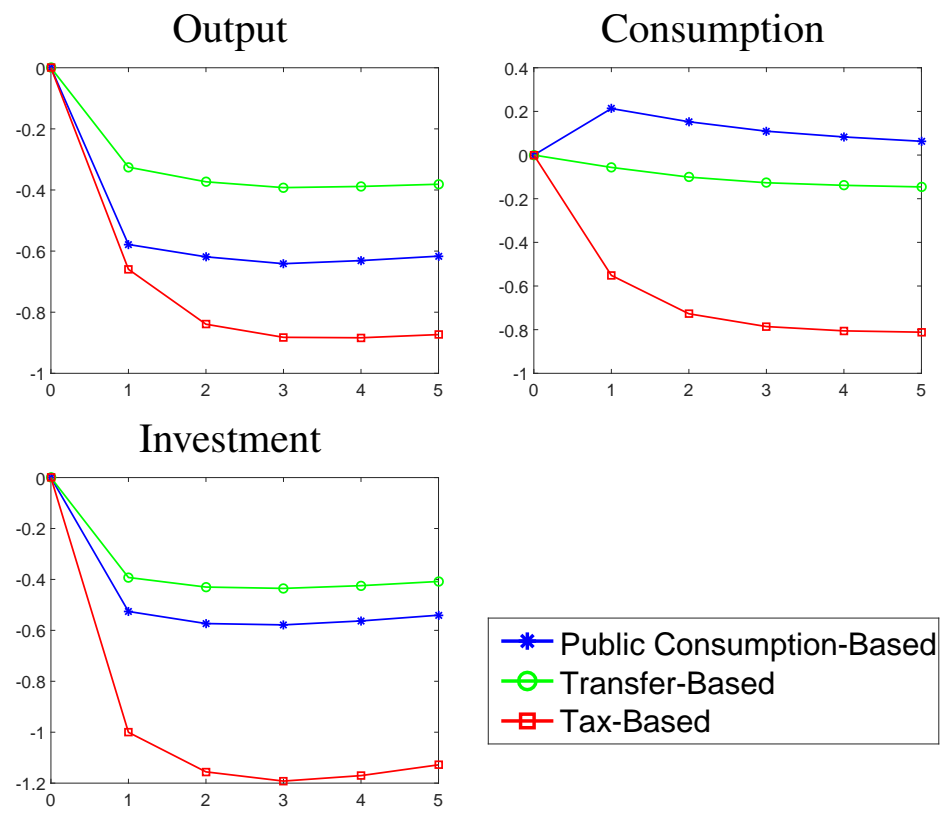

The results on output qualitatively match our empirical simulations. The curvature of the impulse responses is due to the announcements for periods $t+1$ and $t+2$ and is similar to the one we observe in the empirical simulations. $T R B$ and $C I B$ plans are the least harmful in terms of output, while $T B$ plans are the most detrimental. The multiplier of a $T B$ plan is around - 0.6 on impact, and drops below - 0.8 the following years. These multipliers are not far from our empirical estimates in the first three years after the start of the consolidation (between - 0.6 and - 1), but smaller (in absolute value) than our empirical estimates for years 4 and 5, which are around 1.4. Similarly, the output effects of $T R B$ and $C I B$ consolidations are close to the empirical estimates in the first three years (between 0.3 and - 0.6), but - unlike in the empirical analysis - they remain constant in years 4 and 5. Compared to these theoretical results, our empirics predict a faster recovery during $C I B$ and $T R B$ consolidations and a more detrimental effect of $T B$ plans in the medium-term. Remarkably, the model can generate low spending multipliers despite the fact that transfers are not considered government spending.

The results for private consumption are qualitatively consistent with the empirical estimates for $T R B$ and $T B$ consolidations. On impact, $T R B$ consolidations have a consumption multiplier of -0.1 (compared with -0.2 in the empirical estimates) and $T B$ consolidations 
reduce consumption by 0.6 on impact, by 0.8 the following year and slightly less than the 1 percent for the following years, in line with our empirical estimates. The results for $C I B$ consolidations are instead different from those estimated empirically. In the theoretical model consumption rises under $C I B$ plans, the opposite of what we found empirically. This effect on consumption is consistently found in New Keynesian and Neoclassical models, where increases in government spending generate crowding-out effects on consumption. ${ }^{42}$ Interestingly, the simulations for consumption qualitatively match the estimated pattern of consumer confidence presented in the empirical estimates.

The response of investment is qualitatively in line with the empirical estimates. $C I B$ and $T R B$ plans appear to be significantly less harmful for capital investment and their effects are similar to our estimates. Magnitudes, however, are smaller. The multiplier for $T B$ plans on impact is close to the empirical estimates, but in the following years our estimates are 1 percent higher than what predicted by the model. The difference could be partly explained by the fact that we excluded capital taxes from our model, while they are a non-negligible component of tax-based measures in the empirical analysis.

The role of capital Capital accumulation exacerbates the negative effect of direct taxes compared to the model in Section 7.2. As in the basic model, a hike in labor taxes generates a negative substitution effect that leads to lower labor supply, which increases the labor cost for firms, leading to lower labor demand and higher inflation. This, in turn, reduces the marginal return on capital and induces a shift of savings from capital to bonds. In short, when capital is introduced in the model, the negative and persistent shift in labor supply has an amplifying effect on output running through the reduction in investment (due to a lower return of capital) and to higher savings, due to an increase in the interest rate set by the central bank. In the case of a fiscal consolidation implemented through a government spending plan, the same effects are at play. However, because the effect of such consolidation on labor supply is weaker, investment returns respond less. On top of that, the reduction in inflation induces the central bank to lower interest rates. Compared to a tax consolidation, prices fall both because aggregate demand falls and because the marginal cost of production for firms also falls due to the lower rental cost of capital, only partially offset by the wage increase. The lower interest rate increases the consumers' opportunity

\footnotetext{
${ }^{42}$ Galì et al. (2007) eliminate crowding-out by introducing rule-of-thumb consumers and non-competitive labor markets, obtaining an effect that is closer to our empirical estimates. Another possible explanation for the discrepancy between our empirical results and the simulations could be that a fraction of the expenditure reductions included in $C I B$ plans falls on goods that are complements with private consumption. Our model instead assumes separability between private consumption and public spending.
} 
cost of borrowing money, shifting them towards consumption or capital investment.

Non-Ricardian effects The models we have discussed so far feature Ricardian equivalence. We now simulate a model with hand-to-mouth consumers, whose share is calibrated to be $30 \%$ of all households according to the range estimated by Kaplan and Violante (2014). ${ }^{43}$ We report impulse responses in Figure A.8 in Appendix C. As expected, transferbased consolidations are more recessionary and their effect is closer to that of government spending-based plans, consistently with our empirical estimates. ${ }^{44}$ Tax-based consolidations become more recessionary with a multiplier that approaches 1 . We find an even stronger effect of taxes - very close to the empirical estimates - if we increase the share of hand-to-mouth consumers to $40 \%$. Private consumption still increases in response to government spending cuts because of a crowding-in effect. As showed by Galì et al. (2007), this result only breaks down if the labor market is non-competitive.

\section{Conclusions}

This paper contributes to the literature on the effect of fiscal consolidations in three ways. First, we construct a new time-series with over 3500 exogenous shifts in fiscal variables categorized between direct and indirect taxes, transfers, and other government spending for 16 countries for the period 1979-2015. Second, we simoultaneously estimate multipliers for three separate components of the budget: taxes, government transfer and public spending. This is crucial to understand whether previous results on government spending multipliers were driven by counfunding effects of transfers and to draw a straightforward parallel with the theoretical literature. Third, we analytically study the fiscal multipliers in a standard New-Keynsian model, and show that the persistence of fiscal measures explains the heterogeneity in the output effect of different fiscal components.

\section{References}

Aiyagari, S., L. J. Christiano, and M. Eichenbaum (1992). The output, employment, and interest rate effects of government consumption. Journal of Monetary Economics 30(1), 73 - 86.

\footnotetext{
${ }^{43}$ Galì et al. (2007) employ an alternative share of 0.5. Qualitative results are virtually unchanged when we use such calibration.

${ }^{44}$ In order to avoid distortions on hand-to-mouth consumers, we balance the government budget through transfers $\tilde{T}_{t}$ on Ricardian households only.
} 
Alesina, A., S. Ardagna, R. Perotti, and F. Schiantarelli (2002). Fiscal policy, profits, and investment. American Economic Review 92(3), 571-589.

Alesina, A., G. Azzalini, C. Favero, F. Giavazzi, and A. Miano (2016). Is the "how" or the "when" that matters in fiscal adjustments? Working Paper.

Alesina, A., O. Barbiero, C. Favero, F. Giavazzi, and M. Paradisi (2015). Austerity in 2009-2013. Economic Policy 30, 383-437.

Alesina, A., C. Favero, and F. Giavazzi (2015). The output effect of fiscal consolidation plans. Journal of International Economics 96, S19-S42.

Alesina, A., C. Favero, and F. Giavazzi (2017). Austerity. Manuscript.

Alesina, A. F. and S. Ardagna (2009, October). Large Changes in Fiscal Policy: Taxes Versus Spending. NBER Working Papers 15438, National Bureau of Economic Research, Inc.

Alesina, A. F. and S. Ardagna (2012, September). The design of fiscal adjustments. Working Paper 18423, National Bureau of Economic Research.

Barro, R. and C. J. Redlick (2011). Macroeconomic effects from government purchases and taxes. Quarterly Journal of Economics 126(1), 51-102.

Baxter, M. and R. G. King (1993). Fiscal policy in general equilibrium. American Economic Review 83(3), 315-334.

Blanchard, O. and R. Perotti (2002). An empirical characterization of the dynamic effects of changes in government spending and taxes on output. Quarterly Journal of Economics 114(4), 13291368.

Burnside, C., M. Eichenbaum, and J. D. Fisher (2004). Fiscal shocks and their consequences. Journal of Economic Theory 115(1), 89 - 117.

Calvo, G. (1983). Staggered prices in a utility-maximizing framework. Journal of Monetary Economics 12, 383-398.

Chodorow-Reich, G., L. Feiveson, Z. Liscow, and W. Gui Woolston (2012). Does state fiscal relief during recessions increase employment? evidence from the american recovery and reinvestment act. American Economic Journal: Economic Policy 4(3), 118-145.

Christiano, L., M. Eichenbaum, and S. Rebelo (2011). When is the government spending multiplier large? Journal of Political Economy 119(1).

Christiano, L. J. and M. Eichenbaum (1992). Current real-business-cycle theories and aggregate labor-market fluctuations. The American Economic Review 82(3), 430-450.

Clemens, J. and S. Miran (2012, May). Fiscal policy multipliers on subnational government spending. American Economic Journal: Economic Policy 4(2), 46-68. 
Coenen, G., C. J. Erceg, C. Freedman, D. Furceri, M. Kumhof, R. Lalonde, D. Laxton, J. Linde, A. Mourougane, D. Muir, S. Mursula, C. de Resende, J. Roberts, W. Roeger, S. Snudden, M. Trabandt, and J. int Veld (2012). Effects of fiscal stimulus in structural models. American Economic Journal: Macroeconomics 4(1), 22-68.

Denes, M., G. B. Eggertsson, and S. Gilbukh (2013). Deficits, public debt dynamics and tax and spending multipliers. The Economic Journal 123(566), F133-F163.

Devries, P., J. Guajardo, D. Leigh, and A. Pescatori (2011). A new action-based dataset of fiscal consolidation. IMF Working Papers 11/128, 1-90.

European Commission (2015). Taxation trends in the european union. European Commission.

Farhi, E., G. Gopinath, and O. Itskhoki (2014). Fiscal devaluations. Review of Economic Studies 81(2), 725-760.

Farhi, E. and I. Werning (2016). Fiscal multipliers: Liquidity traps fiscal multipliers: Liquidity traps and currency unions. Handbook of Macroeconomics.

Galì, J., J. Lopez-Salido, and J. Valles (2007). Understanding the effects of government spending on consumption. Journal of European Economic Association 5(1), 227-270.

Galì, J. and T. Monacelli (2005). Monetary policy and exchange rate volatility in a small open economy. Review of Economic Studies 73(3), 707-734.

Giavazzi, F. and M. Pagano (1990). Can severe fiscal contractions be expansionary? tales of two small european countries. NBER Macroeconomics Annual, 75-122.

Guajardo, J., D. Leigh, and A. Pescatori (2014). Expansionary austerity? international evidence. Journal of the European Economic Association 12(4), 949-968.

Hernandez de Cos, P. and E. Moral-Benito (2013). Fiscal consolidations and economic growth. Fiscal Studies 34(4), 491-515.

House, C. L., C. Proebsting, and L. L. Tesar (2017). Austerity in the aftermath of the great recession. NBER Working Paper (23147).

Jordà, O. (2005). Estimation and inference of impulse responses by local projections. American Economic Review 95(1), 161-182.

Jordà, O. and A. M. Taylor (2016). The time for austerity: Estimating the average treatment effect of fiscal policy. The Economic Journal 126(590), 219-255.

Kaplan, G. and G. L. Violante (2014). A model of the consumption response to fiscal stimulus payments. Econometrica 82(4), 1199-1239.

Leeper, E. M., T. B. Walker, and S.-C. S. Yang (2013). Fiscal foresight and information flows. Econometrica 81(3), 1115-1145. 
Lemoine, M. and J. Linde (2016). Fiscal consolidation under imperfect credibility. European Economic Review 88, 108 - 141.

Mertens, K. and M. O. Ravn (2013). The dynamic effects of personal and corporate income tax changes in the united states. The American Economic Review 103(4), 1212-1247.

Nakamura, E. and J. Steinsson (2014). Fiscal stimulus in a monetary union: Evidence from us regions. American Economic Review 104(3), 753-92.

OECD (2016). Oecd tax database. OECD.

Pappa, E., R. Sajedi, and E. Vella (2015). Fiscal consolidation with tax evasion and rent seeking. Journal of International Economics 96, S56-S75.

Perotti, R. (2014). Defense government spending is contractionary, civilian government spending is expansionary. IMF Working Paper.

Ramey, V. A. (2011a). Can government purchases stimulate the economy? Journal of Economic Literature 49(3), 673-685.

Ramey, V. A. (2011b). Identifying government spending shocks: It's all in the timing. Quarterly Journal of Economics 126(1), 1-50.

Ramey, V. A. and M. D. Shapiro (1998). Costly capital reallocation and the effects of government spending. Carnegie-Rochester Conference Series on Public Policy 48, 145 - 194.

Ramey, V. A. and S. Zubairy (Forthcoming). Government spending multipliers in good times and in bad: Evidence from u.s. historical data. Journal of Political Economy.

Romer, C. D. and D. H. Romer (2010). The macroeconomic effects of tax changes: Estimates based on a new measure of fiscal shocks. The American Economic Review 100(3), 763-801.

Romer, C. D. and D. H. Romer (2016, October). Transfer payments and the macroeconomy: The effects of social security benefit increases, 1952-1991. American Economic Journal: Macroeconomics 8(4), 1-42.

Schmitt-Grohe, S. and M. Uribe (2003). Closing small open economy models. Journal of International Economics 61(1), 163 - 185.

Serrato, J. C. S. and P. Wingender (2011). Estimating local fiscal multipliers. Working paper.

Smets, F. and R. Wouters (2007, June). Shocks and frictions in US business cycles: a Bayesian DSGE approach. American Economic Review 97(3), 586-606.

Toda, H. Y. and Y. Taku (1995). Statistical inference in vector autoregressions with possibly integrated processes. Journal of Econometrics 66(1-2), 225 - 250.

Woodford, M. (2011). Simple analytics of the government expenditure multiplier. American Economic Journal: Macroeconomics 3(1), 1-35. 


\section{APPENDIX FOR ONLINE PUBLICATION}

\section{Appendix A - Data}

\section{A1 - Motivations Behind Fiscal Consolidations}

We provide some examples of the motivations of fiscal consolidation provided in the budget documents consulted for the data construction. For a complete list of motivations see our data appendix available at www.igier.unibocconi.it/fiscalplans.

\section{Belgium 1992}

From the National Bank of Belgium Annual Report 1992 (p. 17): "The reduction of the public deficit is an urgent matter. This necessity would make it derisory, in Belgium, to adopt any policy of restimulating demand by resorting to the budgetary instrument, or to delay the rehabilitation effort in any way. This is the spirit in which the multi-annual socalled 'convergence' plan prepared by the Government during the summer of 1992 and since approved by the EC Council of Ministers must be examined."

\section{Canada 1991}

From the 1991 Budget Speech, p. 2 "We will put the government finances firmly on the course to a balanced budget... The Expenditure Control Plan announced in the 1990 budget will be extended. The government will legislate mandatory program spending limits... We will severely restrain the operations of government. Operating budgets will be frozen at current levels and the wages and salaries of Cabinet Ministers, Members of Parliament, all Order-in-Council appointments, and all federal public servants will be tightly restrained." The aim of the spending cuts was to "ensure that we achieve key fiscal goals in line with the plan set out in my 1989 and 1990 budgets: We will eliminate new federal borrowing in financial markets after 1993-94” (p. 3).

\section{Finland 2010}

From the Stability Program 2011: “General government finances are in a more vulnerable position from which to meet expenditure pressures and the narrowing of the tax base arising from population ageing. Ensuring the sustainability of public finances now presents a 
greater challenge than before." "Restoring general government finances in Finland will be a particularly challenging task, because the baby boomers are now reaching retirement age.”

\section{France 2011}

From the Stability Programme 2011-2014, April 2011, p. 4: "In this context, the Government has resolved to pursue its fiscal consolidation policy in order to reduce the deficit to $3 \%$ of GDP by 2013, regardless of the economic situation. To this end, the Government intends to stimulate the economy's potential growth by expanding the structural reforms undertaken since 2007, particularly in the areas of education, innovation, research and development, and competition. The Government's strategy in this regard is detailed in the National Reform Programme. The Government has also intensified its efforts to control public spending over the long term, and these efforts began to show results in 2010. Given the already high level of the tax burden in France, the Government is determined to focus its efforts on reducing spending."

\section{Germany 2006}

From the Germany Stability Program 2007 (p. 20): “in the course of the consolidation package implemented by the government in 2006, not only was the excessive deficit reduced, but a decisive step was taken towards the sustainability and long-term recovery of the government finances.”

\section{Italy 1997}

From the 1997 IMF Staff Report reports (pp. 4-5): “The conduct of macroeconomic policies in 1997 was guided by one clear beacon: ensuring Italy's presence among the founding members of EMU... Accordingly, the fiscal retrenchment measures incorporated in the 1997 budget were almost doubled from their originally envisaged size."

\section{United States 1990}

The Omnibus Budget Reconciliation Act 1990 was a five-year fiscal consolidation program enacted on November 5, 1990 (The 1990 Budget Agreement: An interim Assessment, p.6). The act was motivated by deficit reduction, as expressed in the 1991 Economic Report of the President: "The Omnibus Budget Reconciliation Act of 1990 contains the largest 
and most comprehensive deficit reduction package in U.S. history [...] Economic theory and empirical evidence indicate that expectations of deficit reduction in future years, if the deficit reduction commitment is credible, can lower interest rates as financial market participants observe that the government will be lowering its future demand in the credit market”. 


\section{A2 - Data Sources}

As explained in Section 2, the fiscal consolidation episodes refer to the ones gathered by Devries et al. (2011). We have disaggregated the fiscal components by reading the following sources: OECD Country Surveys, IMF Recent Economic Developments reports, Central Bank Macroeconomic reports, Treasury and Economic Ministry reports and European Commission Stability Reports. Other macroeconomic variables used in Figure 2 and Figure 3 are described in the following table:

Table 7: Data Sources

\begin{tabular}{ll}
\hline Variable & Source \\
\hline Nominal GDP & $\begin{array}{l}\text { For all except IRL: OECD Economic Outlook n. 97. } \\
\text { Source for IRL: IMF WEO April 2015. } \\
\text { (GDP, value, market prices) }\end{array}$ \\
Feal GDP & $\begin{array}{l}\text { For all except IRL: OECD Economic Outlook n. 97. } \\
\text { Source for IRL: IMF WEO April 2015. } \\
\text { (GDP, volume, market prices) }\end{array}$ \\
Private Consumption & $\begin{array}{l}\text { OECD Economic Outlook n. 97. } \\
\text { (Private final consumption expenditure, volume) }\end{array}$ \\
& $\begin{array}{l}\text { OECD Economic Outlook n. 97 } \\
\text { (Private Investments). }\end{array}$ \\
Private Investment & $\begin{array}{l}\text { AUT, PRT, ITA, IRL, ESP from ECOFIN AMECO } \\
\text { (Private Investments scaled with Total Investment }\end{array}$ \\
Deflator from same database) \\
Consumer Confidence & $\begin{array}{l}\text { Datastream Code: OCS005Q. } \\
\text { (OECD Consumer Confidence Indicator) }\end{array}$ \\
Datastream Code: OBS085Q. \\
Investment Confidence \\
(OECD Industrial Confidence Indicator) \\
Short-Term Interest Rate
\end{tabular}




\section{Appendix B - Model Appendix}

\section{B1 - Instantaneous multipliers: preferences as in equation (3)}

Household - Household's preferences are:

$$
U\left(C_{t}, N_{t}, G_{t}\right)=\frac{\left[C_{t}^{\gamma}\left(1-N_{t}\right)^{1-\gamma}\right]^{1-\sigma}}{1-\sigma}+v\left(G_{t}\right)
$$

We log-linearize the labor-leisure and the Euler equation to derive respectively:

$$
\begin{gathered}
\frac{N}{1-N} \hat{n}_{t}+\hat{c}=-\frac{1}{1-\tau^{d}} \hat{\tau}^{d}-\frac{1}{1+\tau^{c}} \hat{\tau}^{c}+\hat{w}_{t} \\
((1-\sigma) \gamma-1) \hat{c}_{t}-(1-\gamma)(1-\sigma) \frac{N}{1-N} \hat{n}_{t}-\frac{1}{1+\tau^{c}} \hat{\tau}_{t}^{c}= \\
E_{t}\left[((1-\sigma) \gamma-1) \hat{c}_{t+1}-(1-\gamma)(1-\sigma) \frac{N}{1-N} \hat{n}_{t+1}-\frac{1}{1+\tau^{c}} \hat{\tau}_{t+1}^{c}+\beta\left(R_{t+1}-R\right)-\hat{\pi}_{t+1}\right]
\end{gathered}
$$

Where $\hat{y}_{t}=\log \left(Y_{t} / Y^{s s}\right), \hat{n}_{t}=\log \left(N_{t} / N^{s s}\right), \hat{c}_{t}=\log \left(C_{t} / C^{s s}\right), \hat{\tau}_{t}^{d}=\left(\tau_{t}^{d}-\tau^{d, S S}\right)$ and $\hat{\tau}_{t}^{c}=\left(\tau_{t}^{c}-\tau^{c, S S}\right)$.

Phillips Curve and Policies - Log-linearized New Keynesian Phillips Curve:

$$
\pi_{t}=\beta E_{t} \pi_{t+1}+\kappa \hat{m} c_{t}
$$

where $\kappa=(1-\theta)(1-\beta \theta) / \theta$.

Log-linearized Taylor Rule:

$$
R_{t+1}-R=\rho_{R}\left(R_{t}-R\right)+\frac{1-\rho_{R}}{\beta}\left(\phi_{\pi} \pi_{t}+\phi_{Y} \hat{y}_{t}\right)
$$

where $\phi_{\pi}$ is the coefficient on inflation and $\phi_{y}$ is the response to output deviations from the steady state.

Log-linearized public expenditure process:

$$
\ln G_{t}=\rho_{G} \ln G_{t-1}+\varepsilon_{t}^{G}
$$

Log-linearized market clearing: 


$$
\hat{y}_{t}=(1-g) \hat{c}_{t}+\hat{g}_{t}
$$

where $g=G / Y$ and $\hat{g}_{t}=\left(G_{t} / Y_{t}-g\right)$.

Guess of solutions - Again, guess the following solutions:

$$
\begin{gathered}
\pi_{t}=A_{\pi} \hat{g}_{t}+B_{\pi} \hat{\tau}^{c}+C_{\pi} \hat{\tau}^{d} \\
\hat{y}_{t}=A_{y} \hat{g}_{t}+B_{y} \hat{\tau}^{c}+C_{y} \hat{\tau}^{d}
\end{gathered}
$$

Find multipliers for $\pi-\operatorname{Plug}(23)$ in (25):

$$
A_{y} \hat{g}_{t}+B_{y} \hat{\tau}^{c}+C_{y} \hat{\tau}^{d}=(1-g) \hat{c}_{t}+\hat{g}_{t} \Longrightarrow \hat{c}_{t}=\frac{A_{y}-1}{1-g} \hat{g}_{t}+\frac{B_{y}}{1-g} \hat{\tau}^{c}+\frac{C_{y}}{1-g} \hat{\tau}^{d}
$$

Substitute into (20) and obtain:

$$
A_{\pi} \hat{g}_{t}+B_{\pi} \hat{\tau}^{c}+C_{\pi} \hat{\tau}^{d}=\beta\left(A_{\pi} \rho \hat{g}_{t}+B_{\pi} \rho \hat{\tau}^{c}+C_{\pi} \rho \hat{\tau}^{d}\right)+\kappa \hat{m} c_{t}
$$

Substitute (18) into the equation above to get:

$$
\begin{aligned}
(1-\beta \rho)\left(A_{\pi} \hat{g}_{t}+B_{\pi} \hat{\tau}^{c}+C_{\pi} \hat{\tau}^{d}\right) & =\kappa\left(\frac{N}{1-N}\left(A_{y} \hat{g}_{t}+B_{y} \hat{\tau}^{c}+C_{y} \hat{\tau}^{d}\right)\right. \\
& \left.+\frac{A_{y}-1}{1-g} \hat{g}_{t}+\frac{B_{y}}{1-g} \hat{\tau}^{c}+\frac{C_{y}}{1-g} \hat{\tau}^{d}+\frac{1}{1-\tau^{W}} \hat{\tau}^{d}+\frac{1}{1+\tau^{S}} \hat{\tau}^{c}\right)
\end{aligned}
$$

From which we can find the first three conditions using the method of undetermined coefficients:

$$
\begin{gathered}
(1-\beta \rho) A_{\pi}=\kappa\left(\frac{N}{1-N} A_{y}+\frac{A_{y}-1}{1-g}\right) \\
(1-\beta \rho) B_{\pi}=\kappa\left(\frac{N}{1-N} B_{y}+\frac{B_{y}}{1-g}+\frac{1}{1+\tau^{c}}\right) \\
(1-\beta \rho) C_{\pi}=\kappa\left(\frac{N}{1-N} C_{y}+\frac{C_{y}}{1-g}+\frac{1}{1-\tau^{d}}\right)
\end{gathered}
$$


Which we can simplify into:

$$
\begin{aligned}
A_{\pi} & =\frac{\kappa}{1-\beta \rho}\left(\left(\frac{N}{1-N}+\frac{1}{1-g}\right) A_{y}-\frac{1}{1-g}\right) \\
B_{\pi} & =\frac{\kappa}{1-\beta \rho}\left(\left(\frac{N}{1-N}+\frac{1}{1-g}\right) B_{y}+\frac{1}{1+\tau^{c}}\right) \\
C_{\pi} & =\frac{\kappa}{1-\beta \rho}\left(\left(\frac{N}{1-N}+\frac{1}{1-g}\right) C_{y}+\frac{1}{1-\tau^{d}}\right)
\end{aligned}
$$

Find multipliers for $y-$ Substitute the guesses and the Taylor rule into (19) and find the three multipliers using the method of undetermined coefficients following the procedure presented above for the multipliers on $\pi$.

Government Consumption - Using the method of undetermined coefficients we find:

$$
\begin{gathered}
(1-\rho)((1-\sigma) \gamma-1) \frac{A_{y}-1}{1-g}-(1-\rho)(1-\gamma)(1-\sigma) \frac{N}{1-N} A_{y}= \\
\left(1-\rho_{R}\right)\left(\phi_{\pi} A_{\pi}+\phi_{y} A_{y}\right)-\rho A_{\pi}
\end{gathered}
$$

Substitute the definition of $A_{\pi}$ to get:

$$
A_{y}=\frac{\left(\rho-\left(1-\rho_{R}\right) \phi_{\pi}\right)\left(\frac{\kappa}{1-g}\right)\left(\frac{1}{1-g}\right)-\frac{1}{1-g}(1-\rho)((\sigma-1) \gamma+1)}{\left(\frac{(1-\rho)((1-\sigma) \gamma-1)}{1-g}-(1-\rho)(1-\gamma)(1-\sigma) \frac{N}{1-N}-\left(1-\rho_{R}\right) \phi_{y}+\left(\rho-\left(1-\rho_{R}\right) \phi_{\pi}\right) \frac{\kappa}{1-\beta \rho}\left(\frac{N}{1-N}+\frac{1}{1-g}\right)\right)}
$$

Indirect tax - Using the method of undetermined coefficients we find:

$$
\begin{aligned}
&((1-\sigma) \gamma-1)\left(\frac{B_{y}}{1-g}\right)-(1-\gamma)(1-\sigma) \frac{N}{1-N}\left(B_{y}\right)-\frac{1}{1+\tau^{c}}= \\
& \rho((1-\sigma) \gamma-1)\left(\frac{B_{y}}{1-g}\right)- \rho(1-\gamma)(1-\sigma) \frac{N}{1-N}\left(B_{y}\right) \\
&-\rho \frac{1}{1+\tau^{c}}+\left(1-\rho_{R}\right)\left(\phi_{\pi} B_{\pi}+\phi_{Y} B_{y}\right)-\rho B_{\pi}
\end{aligned}
$$

Substitute the definition of $B_{\pi}$ to get: 


$$
B_{y}=\frac{\frac{1-\rho}{1+\tau^{s}}+\left(\left(1-\rho_{R}\right) \phi_{\pi}-\rho\right) \frac{\kappa}{1-\beta \rho}\left(\frac{1}{1+\tau^{c}}\right)}{\frac{((1-\sigma) \gamma-1)(1-\rho)}{1-g}-\frac{N}{1-N}(1-\gamma)(1-\sigma)(1-\rho)-\left(1-\rho_{R}\right) \phi_{y}-\left(\left(1-\rho_{R}\right) \phi_{\pi}-\rho\right) \frac{\kappa}{1-\beta \rho}\left(\frac{N}{1-N}+\frac{1}{1-g}\right)}
$$

Direct Tax - Using the method of undetermined coefficients we find:

$$
\begin{array}{r}
((1-\sigma) \gamma-1) \frac{C_{y}}{1-g}-(1-\gamma)(1-\sigma) \frac{N}{1-N} C_{y}= \\
\rho((1-\sigma) \gamma-1) \frac{C_{y}}{1-g}-\rho(1-\gamma)(1-\sigma) \frac{N}{1-N} C_{y}+\left(1-\rho_{R}\right) \phi_{\pi} C_{\pi}+\phi_{Y} C_{y}-\rho C_{\pi}
\end{array}
$$

Substitute the definition of $C_{\pi}$ to get:

$$
C_{y}=\frac{\left(\left(1-\rho_{R}\right) \phi_{\pi}-\rho\right) \frac{\kappa}{1-\beta \rho} \frac{1}{1-\tau^{d}}}{\left(\frac{(1-\rho)((1-\sigma) \gamma-1)}{1-g}-(1-\rho)(1-\gamma)(1-\sigma) \frac{N}{1-N}-\phi_{Y}-\left(\left(1-\rho_{R}\right) \phi_{\pi}-\rho\right) \frac{\kappa}{1-\beta \rho}\left(\frac{N}{1-N}+\frac{1}{1-g}\right)\right)}
$$

Figure 5 - In Figure 5 we study the values of multipliers for different persistence levels assuming $\rho_{R}=0$ and $\phi_{y}=0$. Call $\Omega_{G}, \Omega_{\tau^{d}}$ and $\Omega_{\tau^{c}}$ the multipliers for $G, \tau^{d}$ and $\tau^{c}$, respectively

$$
\begin{gathered}
\Omega_{G}=\frac{\left(\rho-\phi_{\pi}\right) \kappa-[\gamma(\sigma-1)+1](1-\rho)(1-\beta \rho)}{(1-\beta \rho)(\rho-1)+(1-g)\left(\rho-\phi_{\pi}\right) \kappa\left(\frac{1}{1-g}+\frac{N}{1-N}\right)} \\
\Omega_{\tau^{d}}=\frac{\left(\phi_{\pi}-\rho\right) \frac{1}{1-\tau^{d}} \frac{\kappa}{1-\beta \rho}}{\left[(1-\sigma) \gamma \tau^{d}-1\right](1-\sigma)-\left(\phi_{\pi}-\rho\right) \frac{\kappa}{1-\beta \rho}\left(1+\frac{N}{1-N}\right)} \\
\Omega_{\tau^{c}}=\frac{\left(\phi_{\pi}-\rho\right) \frac{\kappa}{1-\beta \rho}-(\rho-1)}{\gamma(1-\sigma) \tau^{c}-\left(1+\tau^{c}\right)-\left(1+\tau^{c}\right)\left(\left(\phi_{\pi}-\rho\right) \frac{\kappa}{1-\beta \rho} \frac{1}{1-N}\right)}
\end{gathered}
$$

In order to make the multipliers comparable across components we normalized the $\Omega \mathrm{s}$ to measure a shift of the aggregate fiscal component equivalent to $1 \%$ of GDP. In the case of taxes we plot the multiplier corresponding to a $1 \%$ increase in revenues assuming the tax base is at the steady-state value. 


\section{B2 - AS-AD Model Coefficients}

The AD curve is derived from the linearized Euler equation combined with the Taylor rule. The AS curve derives from a combination of the New Keynesian Phillips Curve and the Taylor rule. The expressions for the AD and AS curves are the following:

$$
\begin{gathered}
A D: \quad \hat{\pi}_{t}=-\frac{1-\rho}{\phi_{\pi}-\rho}\left[D_{y} \hat{y}_{t}+D_{g} \hat{g}_{t}+D_{\tau^{s}} \hat{\tau}_{t}^{s}\right] \\
A S: \quad \hat{\pi}_{t}=\frac{\kappa}{1-\beta \rho}\left[S_{y} \hat{y}_{t}-S_{g} \hat{g}_{t}+S_{\tau^{s}} \hat{\tau}_{t}^{s}+S_{\tau^{w}} \hat{\tau}_{t}^{w}\right]
\end{gathered}
$$

The expressions for the $D$ coefficients are:

$$
\begin{gathered}
D_{y}=\frac{(1-\sigma) \gamma-1}{1-g}-(1-\gamma)(1-\sigma) \frac{N}{1-N}-\frac{\phi_{y}}{1-\rho} \\
D_{g}=\frac{(1-\sigma) \gamma-1}{1-g} \\
D_{\tau^{c}}=\frac{1}{1+\tau^{c}}
\end{gathered}
$$

The expressions for the $S$ coefficients are:

$$
\begin{gathered}
S_{y}=\frac{N}{1-N}+\frac{1}{1-g} \\
S_{g}=\frac{1}{1-g} \\
S_{\tau^{d}}=\frac{1}{1-\tau^{d}} \\
S_{\tau^{c}}=\frac{1}{1+\tau^{c}}
\end{gathered}
$$




\section{B3 - Open Economy Extension}

We extend the closed economy presented in Section 7 by modeling a small open economy that trades goods and one risk free international bond with the rest of the world. The home household solves the following problem

$$
\max _{C_{t}, N_{t}} E_{0} \sum_{t=0}^{\infty} \beta^{t} \frac{\left[C_{t}^{\gamma}\left(1-N_{t}\right)^{1-\gamma}\right]^{1-\sigma}}{1-\sigma}+v\left(G_{t}\right)
$$

s.t. $\left(1+\tau_{t}^{c}\right) C_{t}+\frac{E_{t}^{*}}{P_{t}}\left(1+i_{t}^{*}\right) B_{t}^{*}+\frac{B_{t}}{P_{t}}=\frac{\left(1-\tau_{t}^{d}\right) W_{t}}{P_{t}} N_{t}+\frac{\Pi_{t}}{P_{t}}+\frac{E_{t}^{*}}{P_{t}} B_{t+1}^{*}+(1+i) \frac{B_{t+1}}{P_{t}}++\frac{T R_{t}}{P_{t}}+\frac{\tilde{T}_{t}}{P_{t}}$

where $E_{t}^{*}$ is the nominal exchange rate expressed as unit of home currency per unit of foreign currency. $B_{t}^{*}$ is a risk-free international bond denominated in foreign currency that pays a nominal interest rate $i_{t}^{* 45}$. Consumption $C_{t}$ is an aggregator of foreign and home goods

$$
C_{t}=\left[\gamma_{H}^{\frac{1}{\zeta}} C_{H, t}^{\frac{1-\zeta}{\zeta}}+\gamma_{F}^{\frac{1}{\zeta}} C_{F, t}^{\frac{1-\zeta}{\zeta}}\right]^{\frac{\zeta}{\zeta-1}}
$$

so that $\gamma_{H} \in[0.5,1]$ represents home-bias. The consumption of home and foreign goods are a classic CER aggregator of individual varieties:

$$
C_{k, t}=\left[\int_{0}^{1} C_{k t}(j)^{(\varepsilon-1) / \varepsilon}\right]^{\varepsilon /(\varepsilon-1)}
$$

The rest of the elements in the maximization problem are the exact counterparts of the closed economy in Section 7.

The production function of the firm combines labor input of the home country $N_{t}$, with intermediate inputs $X_{t}$ in Cobb-Douglas form:

$$
Y_{t}=L_{t}^{1-\alpha} X_{t}^{\alpha}
$$

Intermediate inputs $X_{t}$ are an aggregator of a continuum of home and foreign goods with exactly the same form as consumption goods. The firm adjust prices in the currency where the good is produced (producer currency pricing) with a probability $\theta^{p}=0.15$, as in

\footnotetext{
${ }^{45}$ To stabilize the level of foreign debt we assume a debt-elastic interest-rate premium for $i_{t}^{*}$ as in SchmittGrohe and Uribe (2003)
} 
the closed economy benchmark model. We assume that the government expecditure $G_{t}$ is fully home-biased.

We produce impulse response functions of this open economy for 1\% GDP shocks in $G_{t}, \tau_{t}^{d}$, and $\tau_{t}^{c}$, to obtain numerical estimates of GDP fiscal multipliers under different levels of fiscal shock persistence ${ }^{46}$.

The response of the real exchange rate crucially depends on the dynamics of real interest rates differentials between the home country and the rest of the world, and hence on the monetary policy rule and the asset market framework assumed. Under our simulation (with incomplete international asset markets and Taylor rule stabilizing inflation) the real exchange rate appreciates after a cut in government spending, and hence the impact on output is exacerbated compared to a closed economy case. When the cut in government spending is more persistent, on the one hand the larger "crowding-in" effect of home consumers mitigates the impact on GDP. On the other hand, the home currency instantaneously appreciate further due to larger shifts in real rates differentials, causing a larger deterioration of the trade balance. We have verified that the mitigating "crowding-in" effect compensates almost exactly the deterioration of terms of trade, as persistence increases. On the revenues side, wage taxes increase home inflation and decrease the demand of home consumers. As in the case of a spending cut, in an open economy this policy causes a appreciation of the exchange rate that exacerbates the negative effect on output. When the change in wage tax is more persistent, on the one hand demand for home-produced goods falls even more and on the other hand the appreciation worsens the trade balance deficit. This dynamic makes tax rates effects unambiguosuly more recessionary as persistence increases.

Figure A.7 shows that under sufficiently large persisitence of fiscal shocks, the output effect of a government spending cut is less recessionary than a wage tax spike and, if anything, their difference is exacerbated compared to a closed economy model. ${ }^{47}$

Under fixed (or pegged) exchange rate, a cut in government spending lowers aggregate home demand and lowers home expected inflation as in the floating exchange case, but in this case we obtain an improvement in the terms of trade and a depreciation in the real exchange rate through price changes. The latter effects help mitigating the output effect of a government spending cut, compared to a closed economy model. In the case of a wage tax increase, labor supply distortions directly affect the price of goods produced at home. This

\footnotetext{
${ }^{46}$ The calibration of the economy is the same as in Table A.3. The level of foreign debt under steady state and home bias are calibrated to match a 5\% of GDP negative net investment position and a $10 \%$ export over GDP share, as an average of all advanced countries in 2014 (IMF Balance of Payments Statistics).

${ }^{47}$ See Table A.3 for details about the model calibration.
} 
creates both a static distortion in the home labor market and a deterioration of the terms of trade. Compared to a closed-economy model, or an open economy with floating exchange rate, both effects imply a further decrease in output. Hence, even with fixed exchange rates we confirm our main results.

\section{B4 - Household's optimality conditions in the model with capital}

In order to solve the problem, we can set up the following Lagrangian:

$$
\begin{aligned}
& \mathscr{L}=E_{0} \sum_{t=0}^{\infty} \beta^{t} U\left(C_{t}, N_{t}, G_{t}\right)+ \\
& E_{0} \sum_{t=0}^{\infty} \beta^{t} \lambda_{t}\left(\left(1-\tau_{t}^{d}\right) w_{t} N_{t}+r_{t} K_{t}+\left(1+i_{t}\right) \frac{B_{t}}{P_{t}}+\frac{\Pi_{t}}{P_{t}}+T_{t}-\left(1+\tau_{t}^{c}\right) C_{t}-I_{t}-\frac{B_{t+1}}{P_{t}}\right) \\
& \\
& \quad+E_{0} \sum_{t=0}^{\infty} \beta^{t} \mu_{t}\left(I_{t}+(1-\delta) K_{t}-\phi\left(\frac{I_{t}}{K_{t}}\right) K_{t}-K_{t+1}\right)
\end{aligned}
$$

The agent chooses respectively $C_{t}, N_{t}, B_{t+1}, K_{t+1}, I_{t}$ according to the following first order conditions:

$$
\begin{gathered}
U_{c}\left(C_{t}, N_{t}, G_{t}\right)=\lambda_{t}\left(1+\tau_{t}^{c}\right) \\
U_{n}\left(C_{t}, N_{t}, G_{t}\right)=\lambda_{t}\left(1-\tau_{t}^{d}\right) w_{t} \\
\lambda_{t}=\beta E_{t}\left[\lambda_{t+1} \frac{\left(1+i_{t+1}\right)}{\left(1+\pi_{t+1}\right)}\right] \\
\mu_{t}=\beta E_{t}\left[\lambda_{t+1} r_{t+1}\right]+\beta E_{t}\left[\begin{array}{l}
\left.\mu_{t+1}\left(1-\delta-\frac{\sigma_{I}}{2}\left(\frac{I_{t}}{K_{t}}-\delta\right)^{2}+\sigma_{I}\left(\frac{I_{t}}{K_{t}}-\delta\right) \frac{I_{t}}{K_{t}}\right)\right] \\
\lambda_{t}=\mu_{t}\left[1-\sigma_{I}\left(\frac{I_{t}}{K_{t}}-\delta\right)\right]
\end{array}\right.
\end{gathered}
$$

Equation (27) determines the labor/leisure choice in a competitive labor market; (28) is the Euler equation where $\pi_{t}$ is inflation defined as $P_{t+1} / P_{t}-1$. Equations (29) and (30) describe the capital and investment decisions. 


\title{
Appendix C - Additional Tables and Figures
}

\author{
Fiscal Consolidation - Time Series
}

Figure A.1: Fiscal Consolidations in Europe and the United States 1980-2014

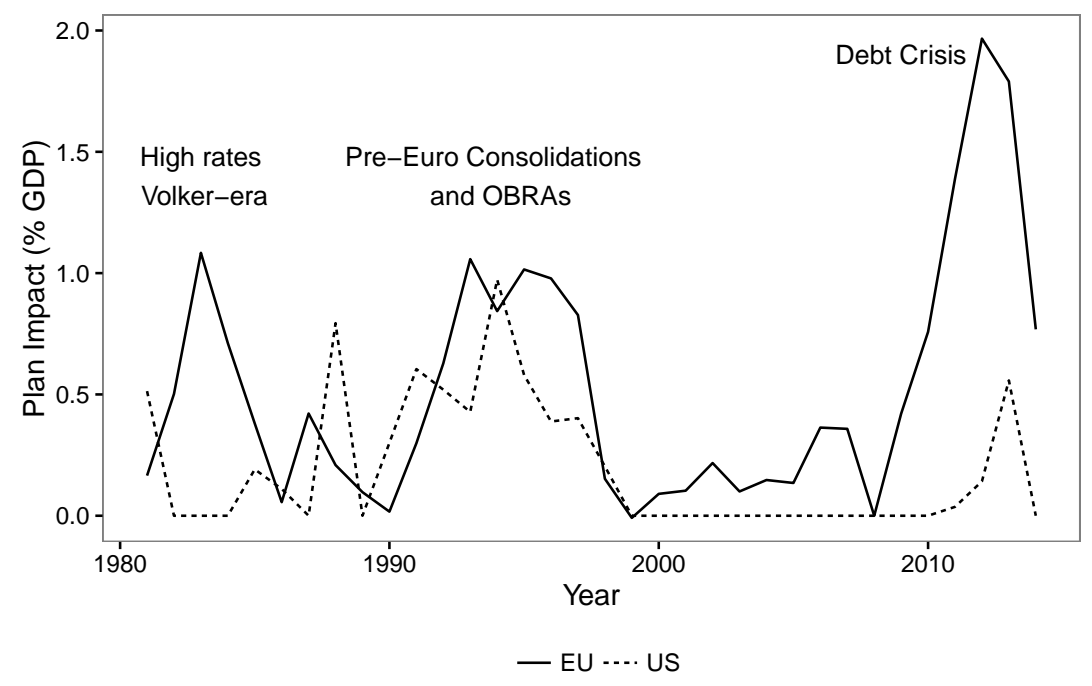

Every year displays the average implemented consolidation as a combination of unexpected measures and measures that were announced in previous years, but are implemented in the current year. The EU time series plots the average implemented consolidation across all EU countries in our sample. The average size of fiscal adjustments is correlated between the two areas. In Europe, however, the first wave of fiscal consolidation happened in the mid 1980s, when countries with large public debts responded to rising real rates. The US postponed fiscal adjustment by about a decade when the OBRA 1990 and OBRA 1993 plans were introduced. Large adjustments were further implemented in Europe in the 1990s to meet the criteria required to join the monetary union and in response to the 1992-93 currency crises. Fiscal action was mild in Europe in the early 2000s and non-existent in the US. Large fiscal measures were adopted by most European countries during the 2010-12 European debt crisis, a period of GDP contraction. A peak average adjustment of almost $2 \%$ of GDP was reached in 2012. Total implemented measures have been declining since then. The US also implemented a large consolidation during the recovery from the Great Recession of 2007-2009. 


\section{Short-term Interest Rate}

Figure A.2: Short-Term (3 months) Interest Rate Response to Different Fiscal Plans

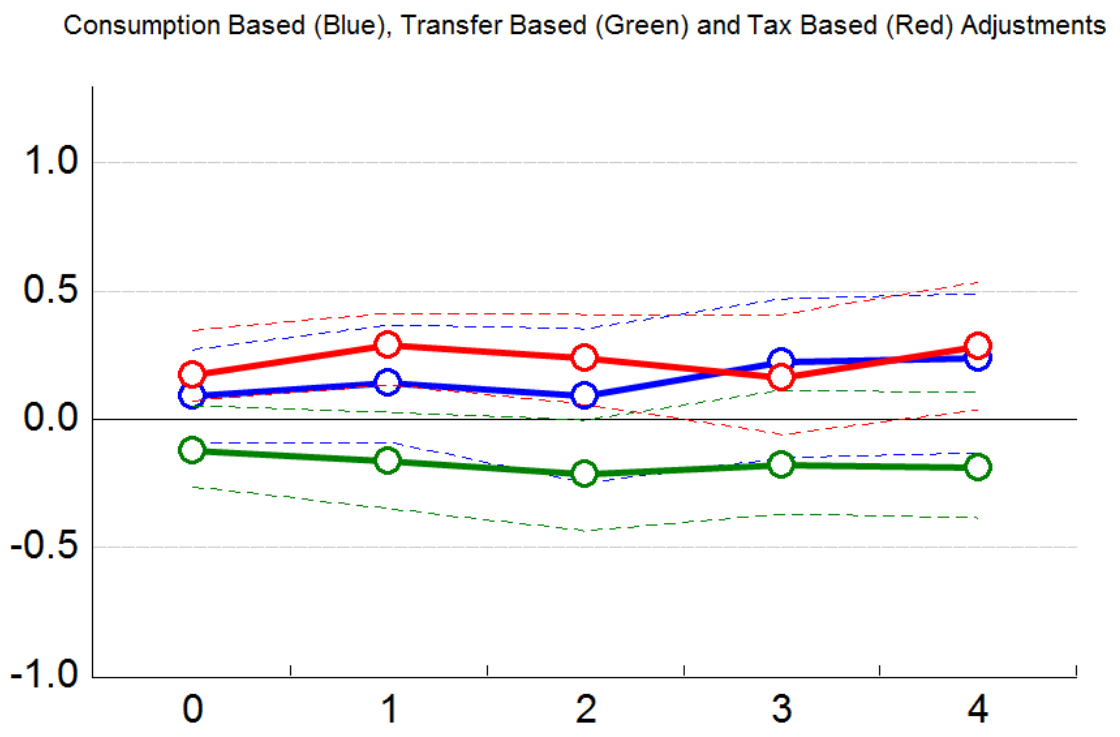

Source: OECD Economic Outlook n. 97. Short-term interest rates are based on threemonth money market rates where available. Typical standardized names are "money market rate" and "treasury bill rate". 


\section{Pre-Crisis Sample (1979-2007)}

Figure A.3: Impulse Response Functions
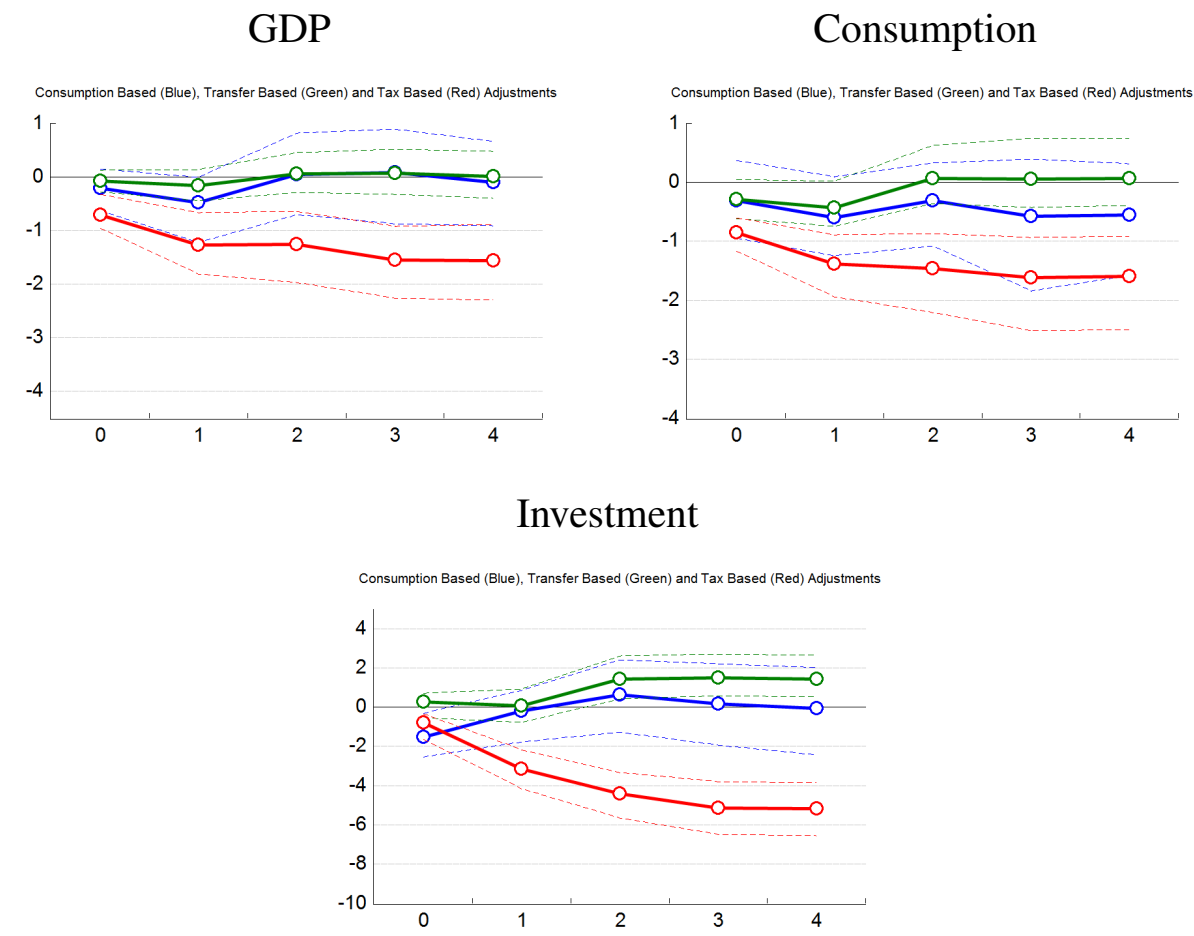

Note. Impulse response functions computed on the sample 1979-2007. 


\section{Excluding Marginal Cases when Labelling Plans}

Figure A.4: Impulse Response Functions

\section{GDP}

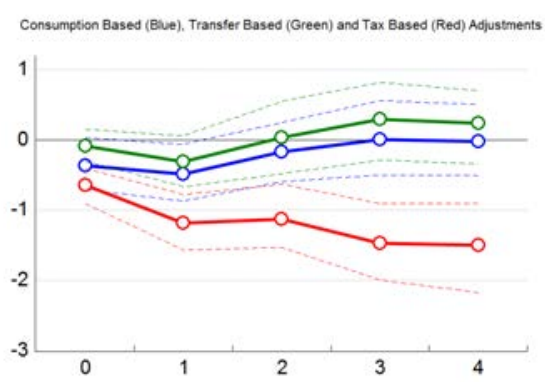

Consumption

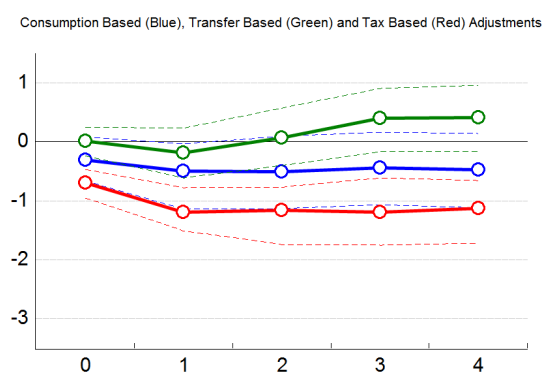

Investment

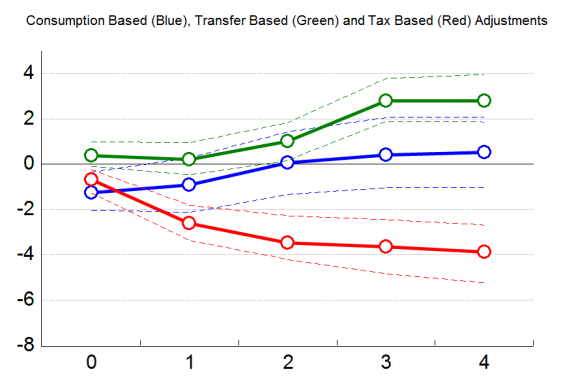

Note. Impulse response functions computed on the sample 1979-2014. We excluded all plans where the difference between the shares of the largest two components is smaller than $10 \%$. 
Excluding episodes whose dominant fiscal component is lower than 50\% of the consolidation

Figure A.5: Impulse Response Functions

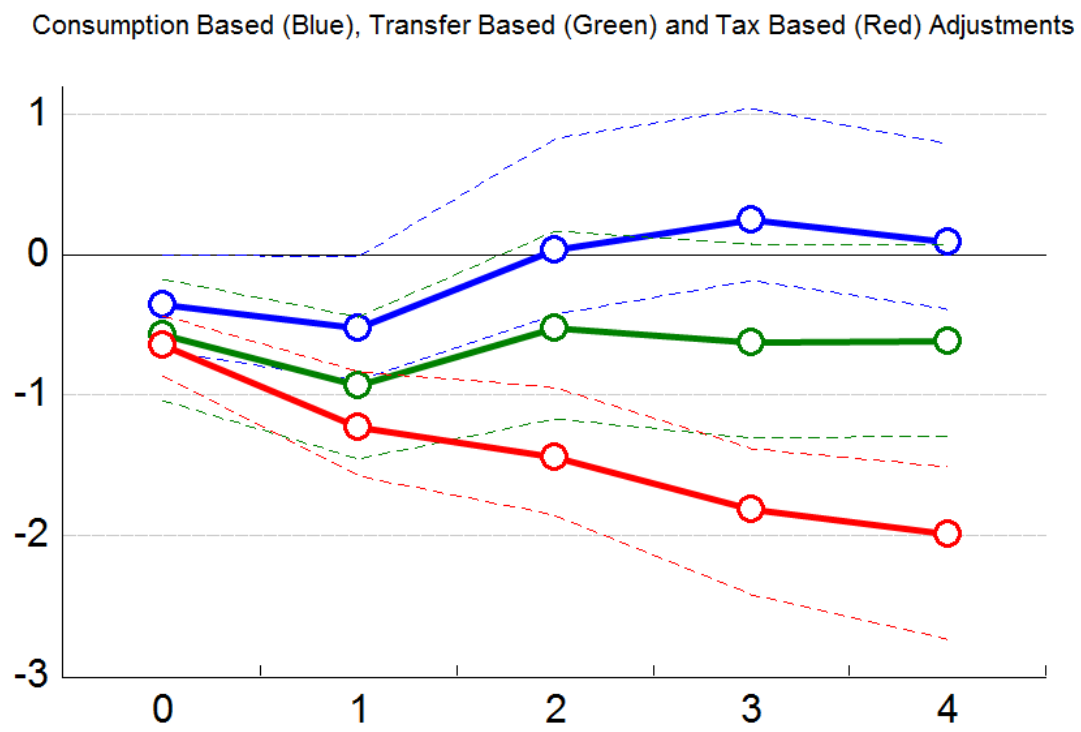

Note. Impulse response function computed on the sample of consolidation episodes excluding those whose dominant fiscal component is lower than 50 


\section{Instantaneous Multipliers with Alternative Taylor Rule $\left(\phi_{y}=0.125\right)$}

Figure A.6: Multipliers with monetary policy response to output

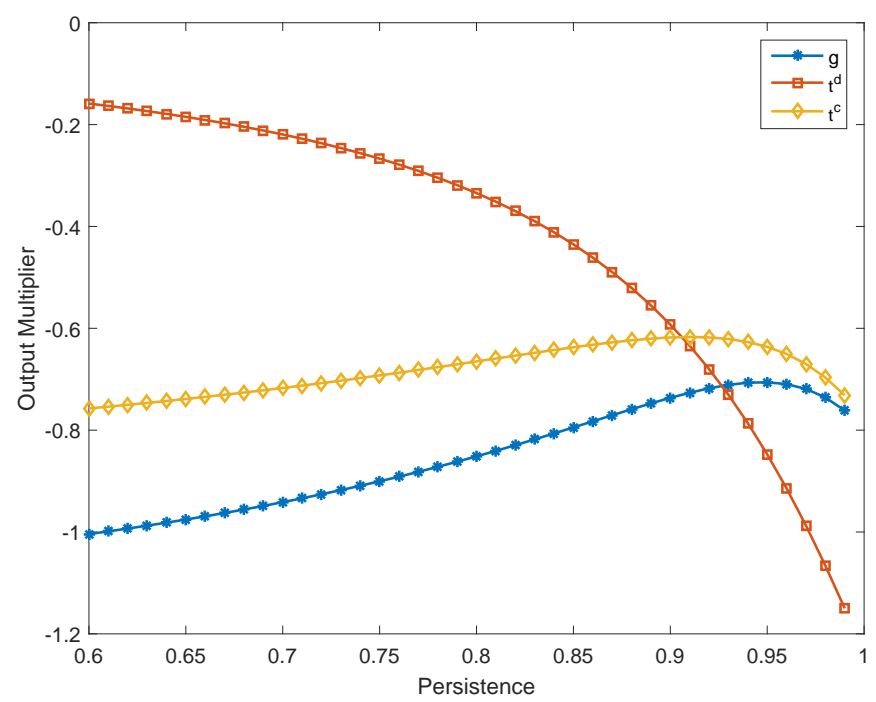

Notes: the Figure shows the magnitude of the instantaneous multipliers as a function of $\rho$ when we adopt the same calibration as in Christiano et al. (2011). In order to make the multipliers comparable across components, we compute the responses of output to a shift of each fiscal component equivalent to $1 \%$ of GDP. Therefore, in the case of taxes we plot the multiplier corresponding to a $1 \%$ increase in revenues over GDP, assuming the tax base is at the steady-state level. 
Figure A.7: Multipliers in an Open Economy

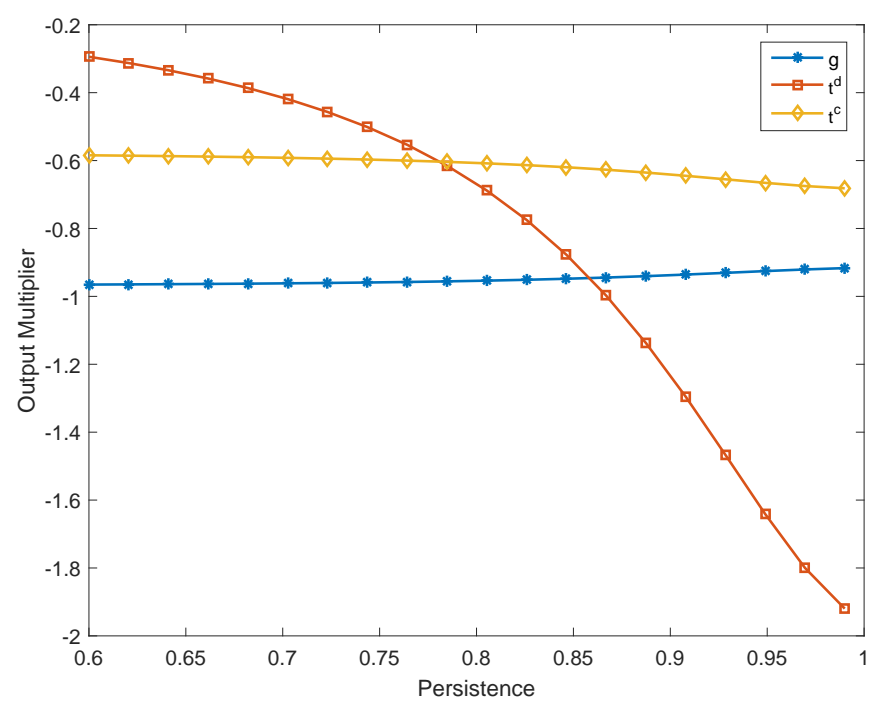

Notes: the Figure shows the magnitude of the instantaneous multipliers as a function of $\rho$ when we adopt the same calibration as in Christiano et al. (2011). In order to make the multipliers comparable across components, we compute the responses of output to a shift of each fiscal component equivalent to $1 \%$ of GDP. Therefore, in the case of taxes we plot the multiplier corresponding to a $1 \%$ increase in revenues over GDP, assuming the tax base is at the steady-state level.

We plot the instantaneous (period 1) effect of each fiscal variable when we simulate a first-order linearization of the model.

\section{Instantaneous Multipliers in an Open Economy with External Debt}




\section{New Keynesian Model with Hand-to-mouth Consumers}

Figure A.8: Model Simulations
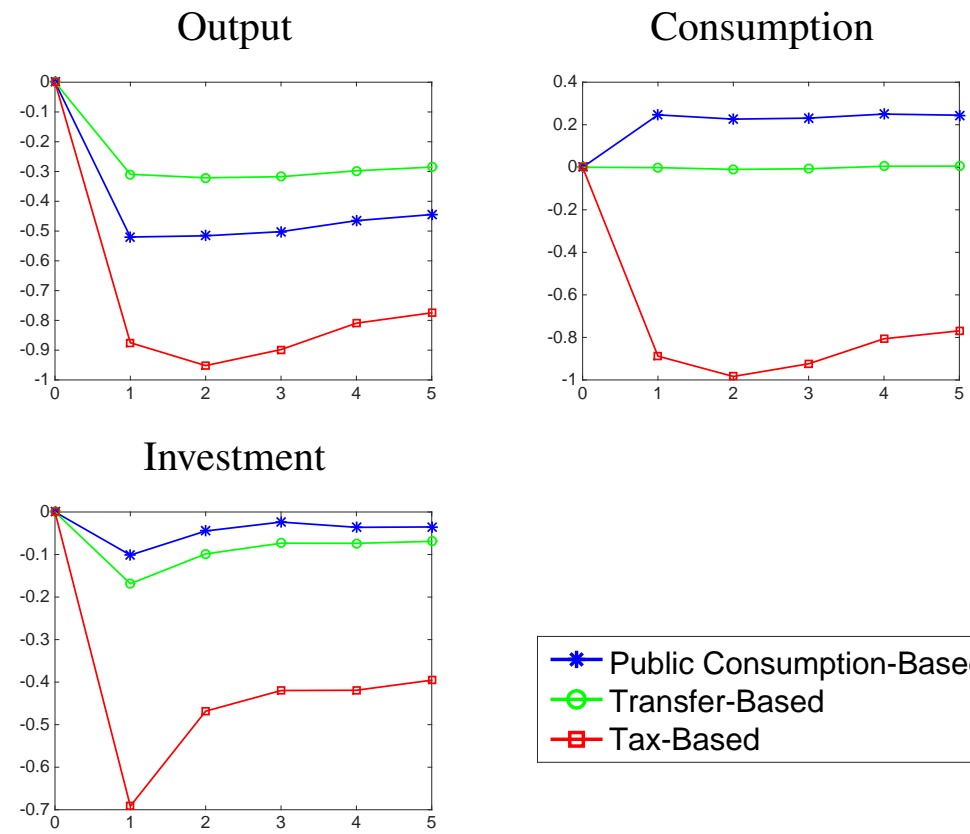

*-Public Consumption-Based - - Transfer-Based

$\square$ Tax-Based 


\section{Country-specific Inter-temporal Correlation}

Table A.1: Inter-temporal Correlation by Country: 1981-2014

\begin{tabular}{ccccccccc} 
& AUS & AUT & BEL & CAN & DEU & DNK & ESP & FIN \\
\hline \hline$\varphi_{1}$ & 0.48 & 0.36 & 0.14 & 1.34 & -0.10 & 0.48 & 0.27 & 0.09 \\
& $(0.19)$ & $(0.08)$ & $(0.14)$ & $(0.17)$ & $(0.12)$ & $(0.13)$ & $(0.06)$ & $(0.12)$ \\
$\varphi_{2}$ & -0.23 & 0 & 0.11 & 0.51 & -0.03 & -0.02 & 0.06 & -0.01 \\
& $(0.14)$ & $(0.04)$ & $(0.03)$ & $(0.11)$ & $(0.07)$ & $(0.08)$ & $(0.02)$ & $(0.02)$ \\
\hline & & & & & & & & \\
& FRA & GBR & IRL & ITA & JPN & PRT & USA & SWE \\
\hline \hline$\varphi_{1}$ & 0.46 & 0.35 & 0.21 & -0.26 & 0.25 & 0.89 & 0.47 & 0.57 \\
& $(0.09)$ & $(0.22)$ & $(0.04)$ & $(0.07)$ & $(0.03)$ & $(0.29)$ & $(0.35)$ & $(0.11)$ \\
$\varphi_{2}$ & 0.14 & 0.07 & 0 & -0.02 & 0 & 0.12 & 0.34 & 0.34 \\
& $(0.05)$ & $(0.18)$ & $(0.00)$ & $(0.04)$ & $(0.00)$ & $(0.10)$ & $(0.28)$ & $(0.08)$ \\
\hline
\end{tabular}

We report estimates of the correlation for one- and two-years ahead announcements for each country. We report a coefficient of zero, with no standard error, whenever there are too few observations available for estimation. Canada records a cumulative response (the sum of the responses of oneand two-year ahead announcements to an unanticipated correction) which is above unity. This means that, on average, Canada back-loads its plans, announcing that the largest fraction of a three-year plan will be implemented in the second and third year. Most countries feature a positive but milder response of announced measures to current unanticipated ones. This correlation is not statistically different from zero in Great Britain and in the United States, where fiscal policy corrections appear to be implemented mainly via unanticipated measures. At the opposite end of the spectrum lie Germany and Italy, where one- and two-year ahead announcements are negatively correlated with unanticipated measures - though not significantly in the case of Germany and significantly, though only at one-year ahead horizon, in the case of Italy. This suggests that at least part of a typical Italian stabilization is transitory. 


\section{Fiscal Consolidations and Structural Reforms}

Table A.2: Fiscal consolidations and structural reforms

\begin{tabular}{lccccccc} 
& New plan & TB & EB & DB & IB & CB & TRB \\
\hline Product Market Reforms & -0.247 & 0.564 & -0.564 & 0.850 & 0.00405 & 0.309 & -0.832 \\
& $(0.381)$ & $(0.625)$ & $(0.625)$ & $(0.786)$ & $(0.709)$ & $(0.635)$ & $(0.603)$ \\
Observations & 484 & 157 & 157 & 157 & 157 & 157 & 157 \\
& & & & & & & \\
Labor Market Reforms & -0.514 & 0.606 & -0.606 & 1.077 & -0.393 & 0.405 & -0.927 \\
& $(0.544)$ & $(1.061)$ & $(1.061)$ & $(1.267)$ & $(1.243)$ & $(0.911)$ & $(0.913)$ \\
Observations & 415 & 135 & 135 & 135 & 135 & 135 & 135 \\
\hline \hline
\end{tabular}

Notes: A negative change in the dependent variables signals a reform toward more open markets. 


\section{Calibration}

Table A.3: Calibration

\begin{tabular}{ccc}
\hline Parameter & Value & Description \\
\hline \hline$\beta$ & 0.99 & Discount factor (quarterly) \\
$\sigma$ & 2 & Inverse inter-temporal elasticity of substitution \\
$\gamma$ & 0.29 & Utility Parameter \\
$\rho$ & 0.99 & Persistence of Fiscal Variables \\
$\sigma_{I}$ & 17 & Investment adjustment cost parameter \\
$G_{s S} / Y_{s s}$ & 0.2 & Government consumption (\% of GDP) \\
$T_{s S} / Y_{s s}$ & 0.2 & Transfers (\% of GDP) \\
$\tau_{S S}^{d}$ & 0.363 & Average Income tax rate (2000 Average from OECD (2016)) \\
$\tau_{S S}^{c}$ & 0.199 & Indirect tax rate (2000 average from European European Commission (2015)) \\
$\alpha$ & 0.3 & Capital share \\
$\theta$ & 0.85 & Degree of price stickiness (quarterly) \\
$\theta_{w}$ & 0.85 & Degree of wage stickiness (quarterly) \\
$A$ & 1 & Total factor productivity \\
\hline & & Open Economy \\
$\gamma_{H}$ & 0.9 & Home bias \\
$\xi$ & 2 & Elasticity of substitution (CES) \\
$\xi$ & 2 & Flasticity of substitution in aggregator of home and foreign goods \\
$\bar{B}^{s s}$ & 0.1 & Foreign Debt in steady state \\
\hline
\end{tabular}

Notes: we follow calibrations in Christiano et al. (2011) and Galì et al. (2007)for most parameters. Average tax rates are calibrated using data from OECD (2016) and European Commission (2015). 


\section{Share of Fiscal Components in Each Type of Plan}

Table A.4: Share of Fiscal Variables in Each Plan Type

\begin{tabular}{lcccc}
\hline$\phi^{Z, J B}$ & $\tau^{d}$ & $\tau^{c}$ & $G$ & $T$ \\
\hline \hline$T B$ & 0.37 & 0.29 & 0.20 & 0.14 \\
$C B$ & 0.04 & 0.13 & 0.67 & 0.17 \\
$T R B$ & 0.09 & 0.10 & 0.26 & 0.55 \\
\hline \hline
\end{tabular}

Notes: shares are computed over the total amount of measures that we were able to classify. This is done to make sure that they sum to 1 in the calibration. 